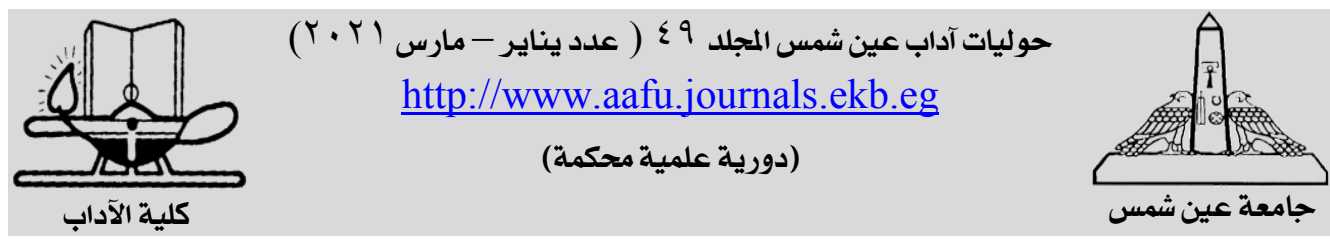

\title{
تأثير الانتماء الوطني في الاتجاه نهو المخاطرة لدى منتسبي مديرية الدفاع المدني
}

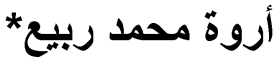

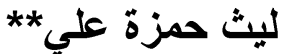 \\ كلية الآداب ـ قسم التاريخ - جامعة بغداد- جمهورية العراق \\ aaammmrrrтrт@gmail.com
}

layth.altameemi@qu.edu.iq

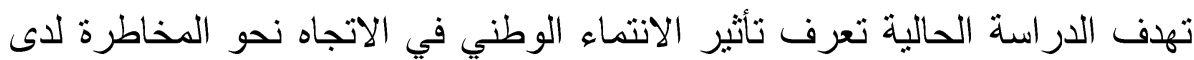

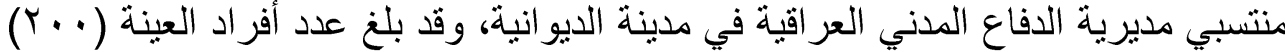
منتسب اختيروا بالطريقة التشوائية. ولقياس هذا التئية الهدف تم بناء مقياس الانتماء الوطني

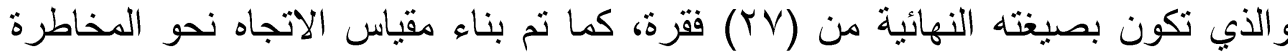

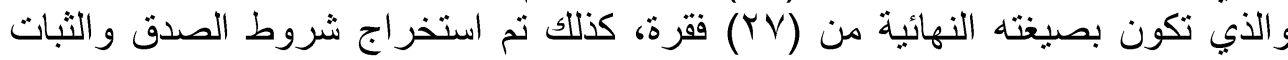

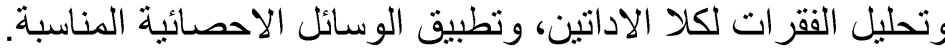

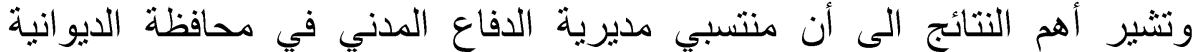

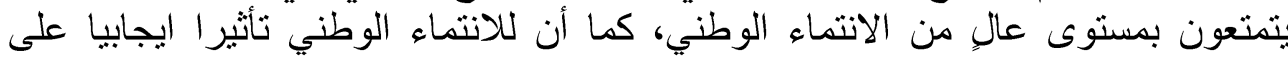

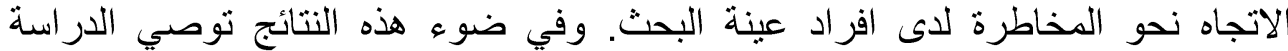

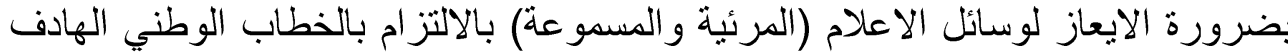

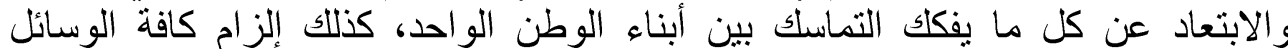

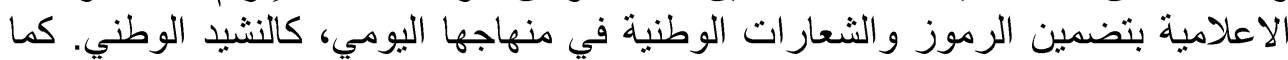

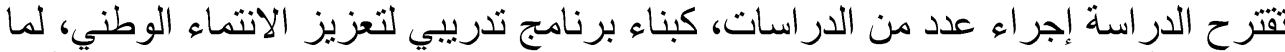

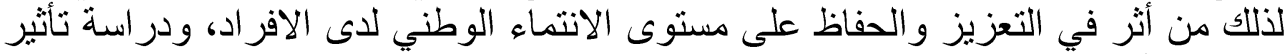

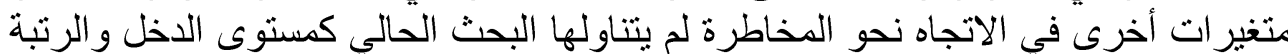

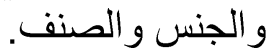


مشكلة البحث : يشكل الإنتماء أحد الجوانب القولة الإنة المدفوعة بدافع شديد الإلحاح لإشباع

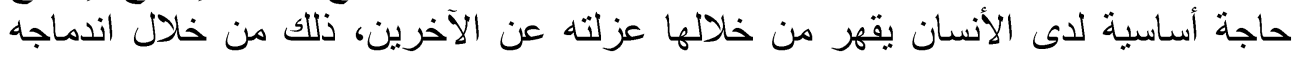

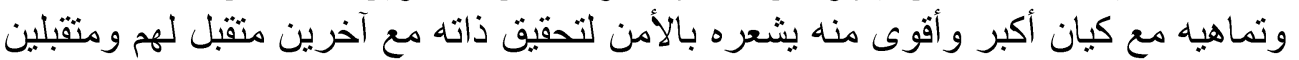

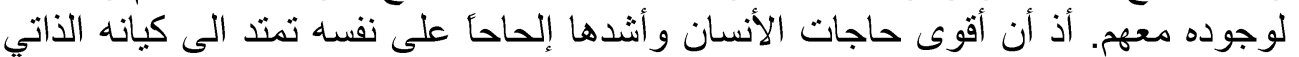

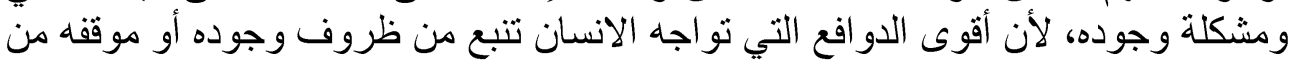

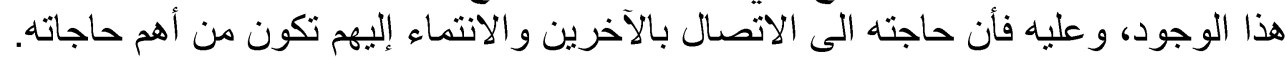

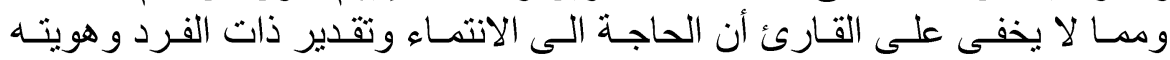

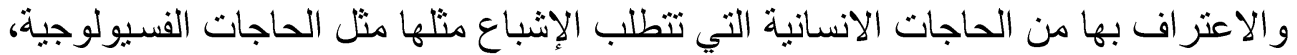

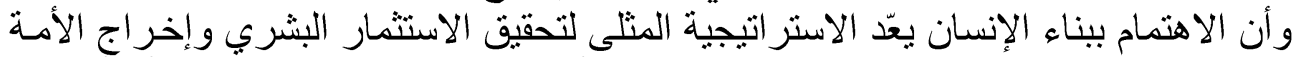

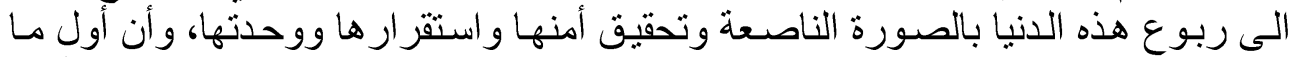

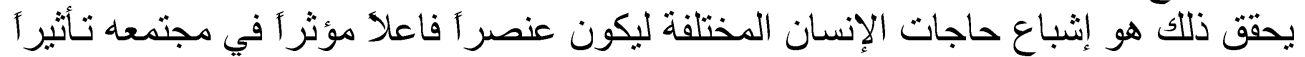

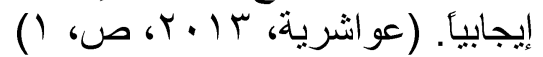

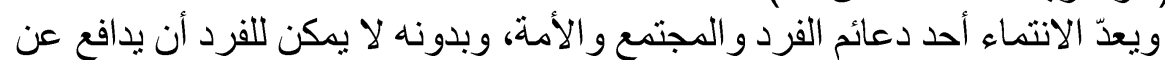

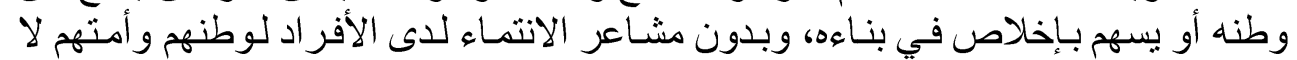

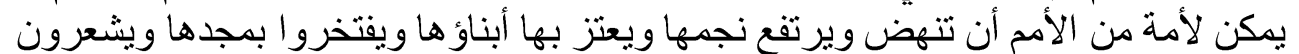

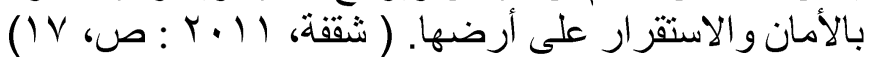

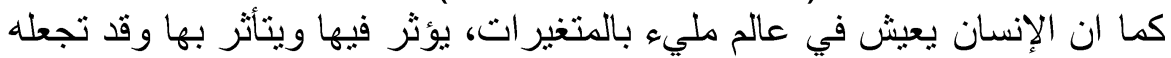

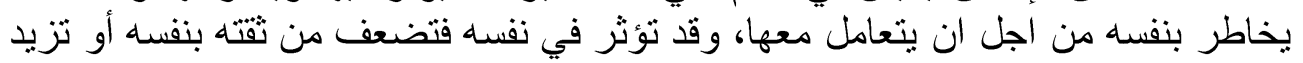

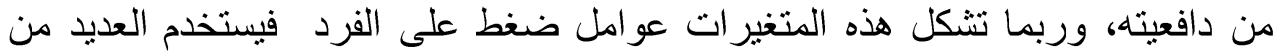

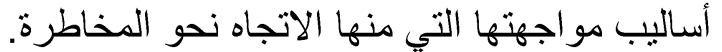

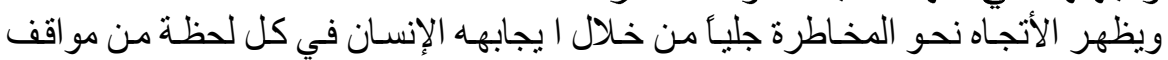

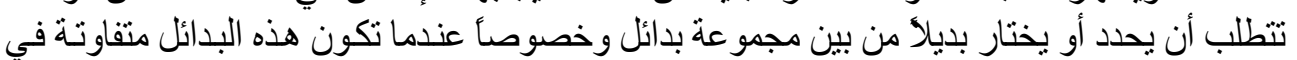

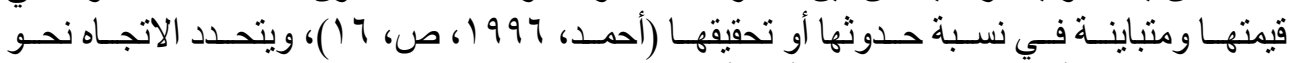

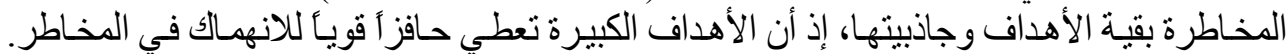

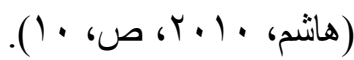
وقد لا يكون هناك معنى للحياة ولن يكون هناك دافع للحياة دون مخاطرة، و القيام

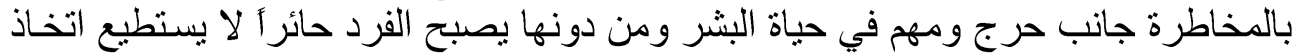

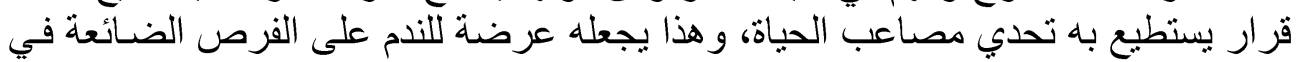

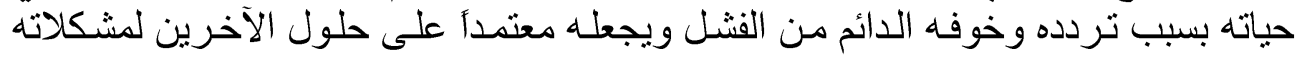
الخاصة. (Carny, 19vo, p.

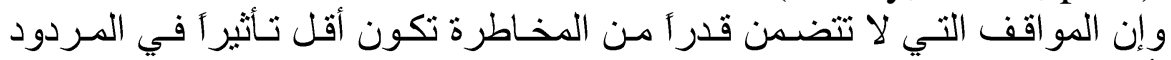

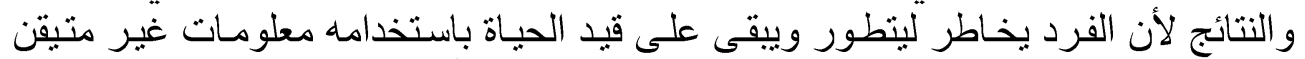

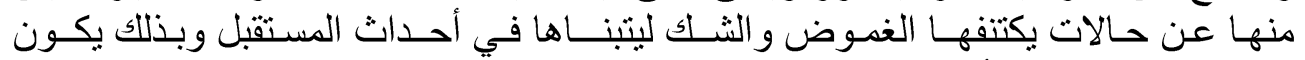

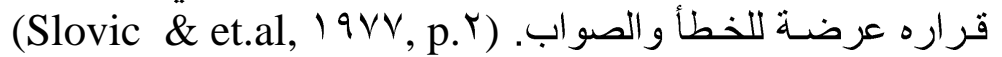

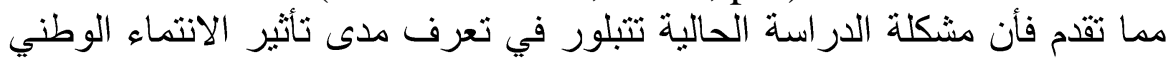

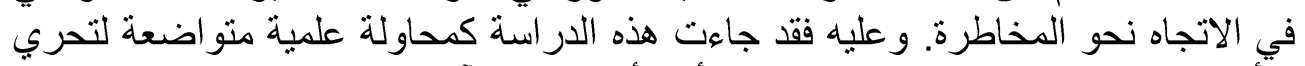

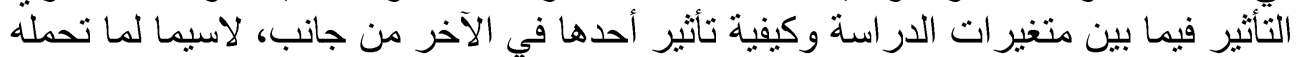

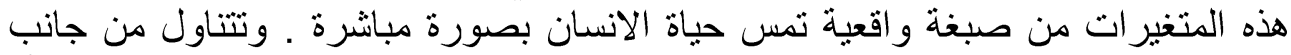

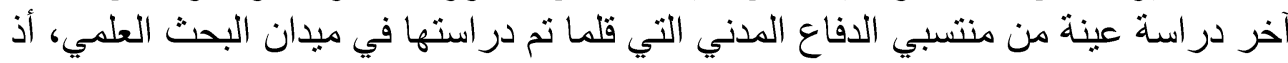

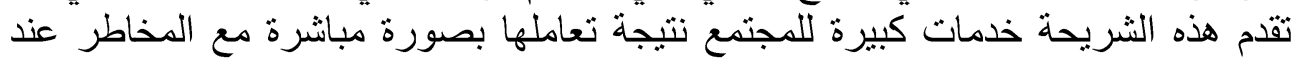




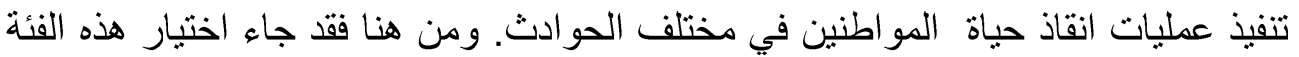

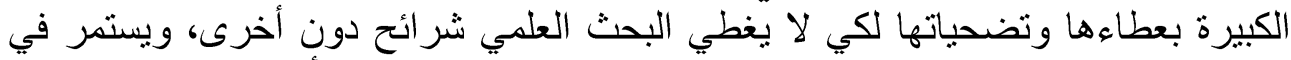

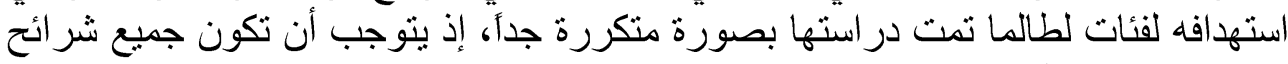
المجتمع تحت انظار الباحثين.

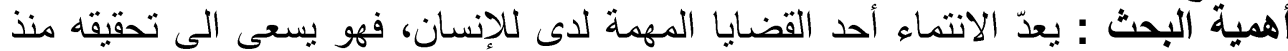

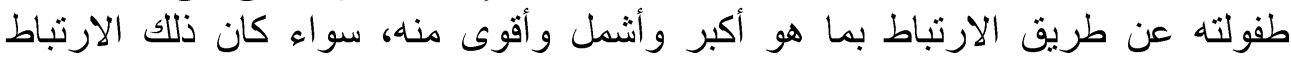

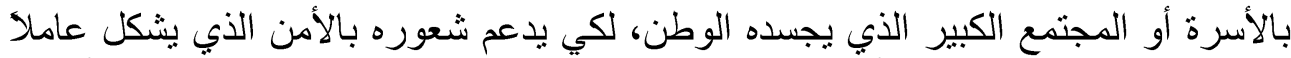

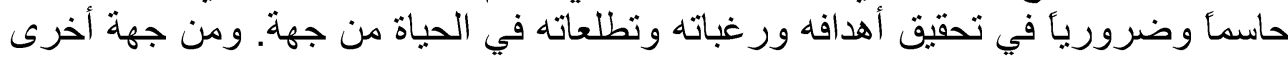

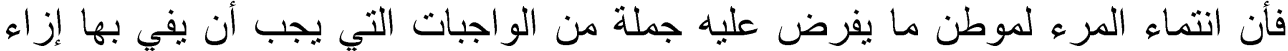

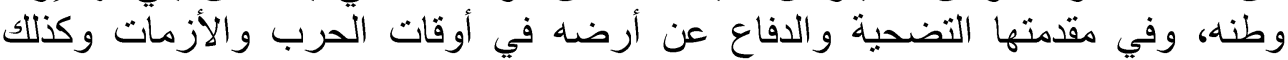

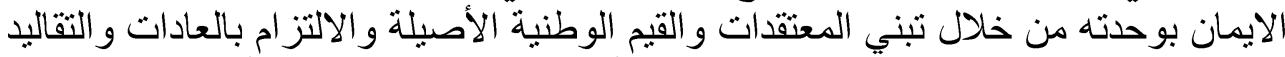

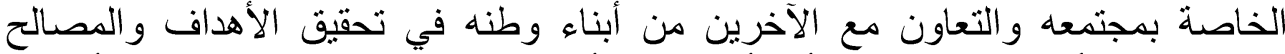

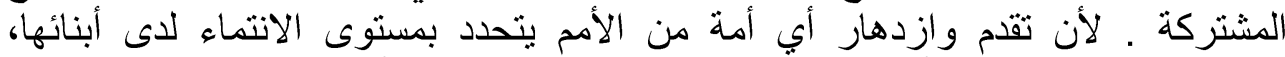

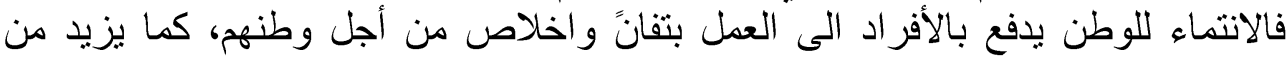
عزيمتهم ومثابرتهم على البناء ومواكبه التطورات السريعة التي تحدث من حولثن التهم في مختلف الميادين.

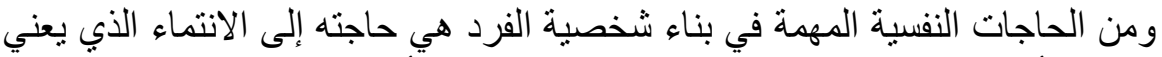

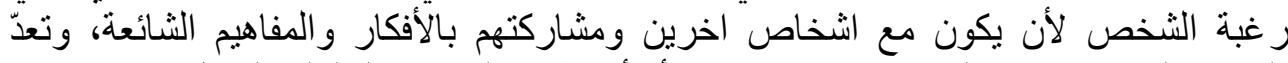

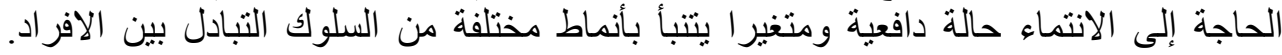

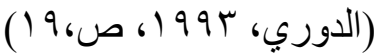

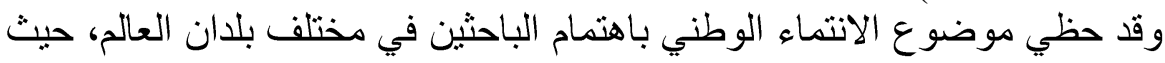

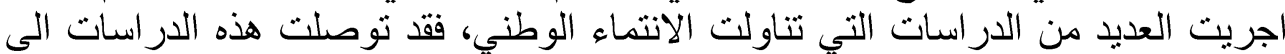

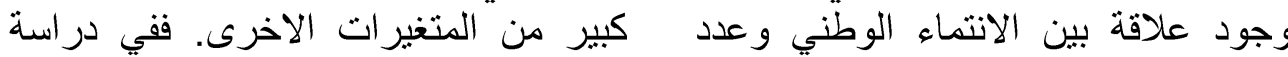

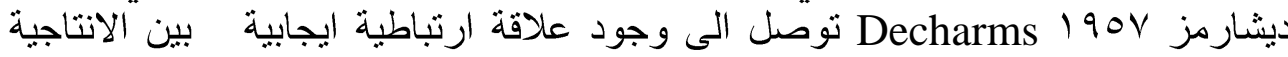

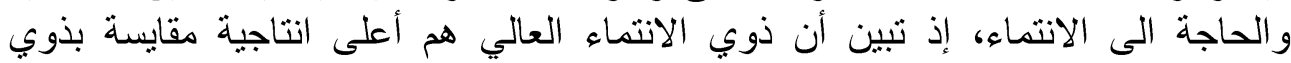

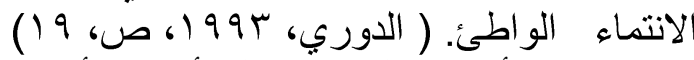
وقد أثنارت الدراسأت إلى أهمية الأسرة في غرس مفهوم الانتماء الوطني في نفوس

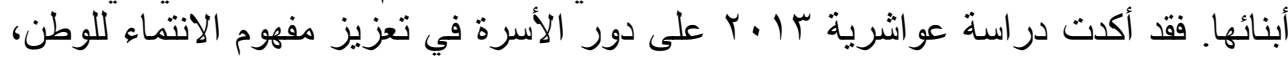

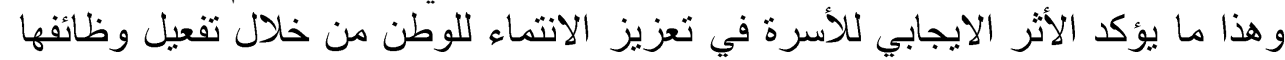

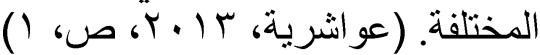

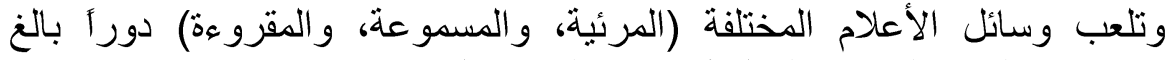

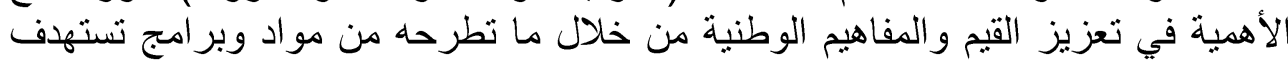

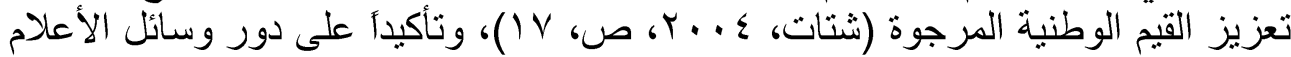

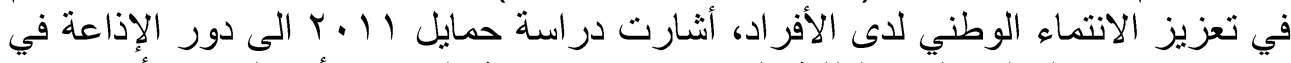

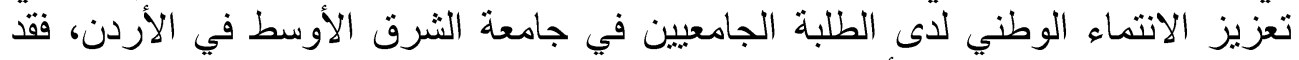

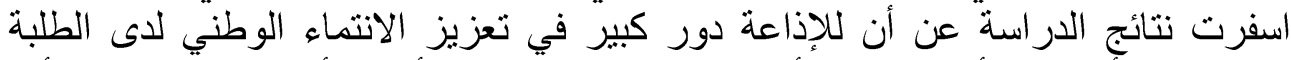

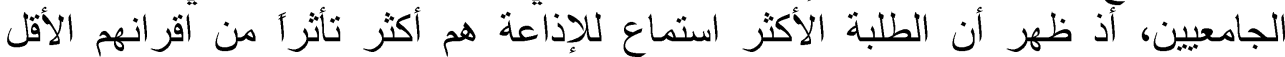

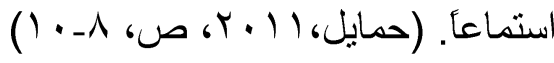


كما أكدت الدراسات على أهمية دور المؤسسات التعليمية والتربوية كذلك المناهج

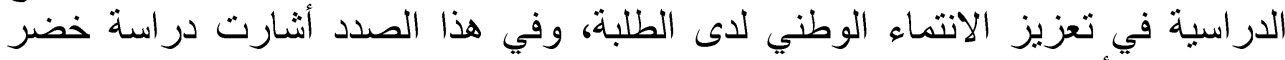

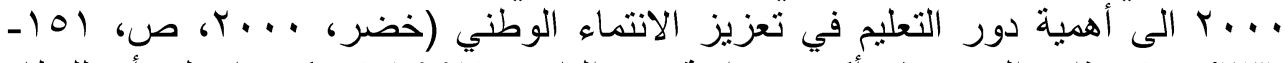

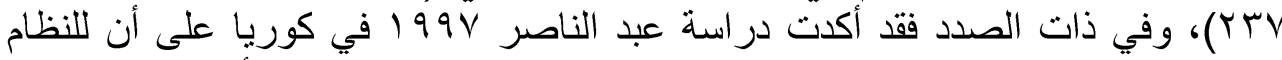

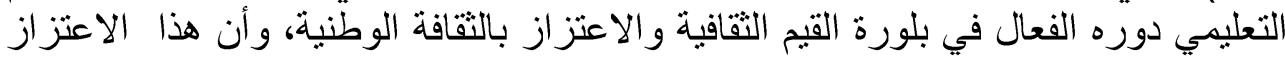

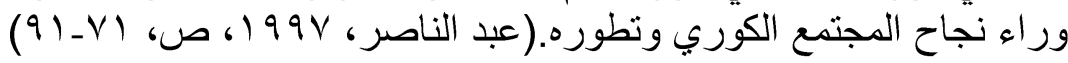

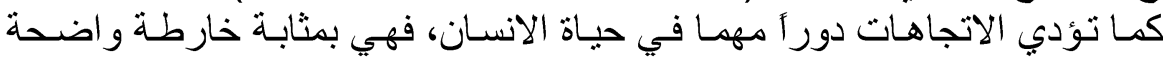

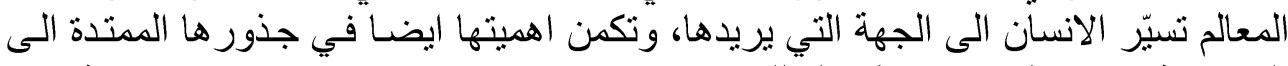

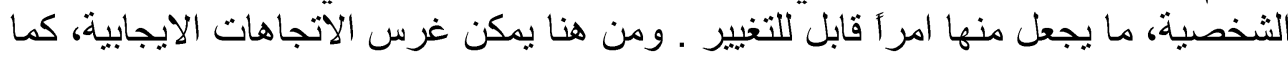

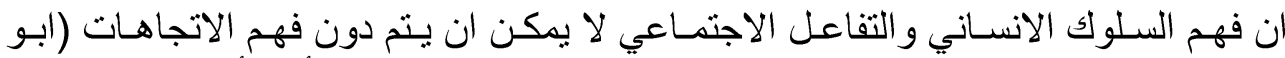

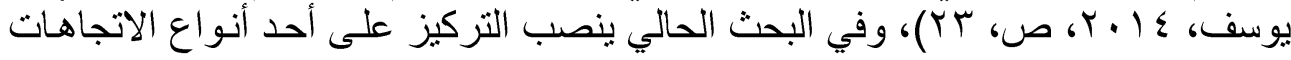
وهو الاتجاه نحو المخاطرة.

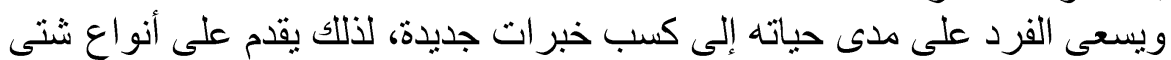

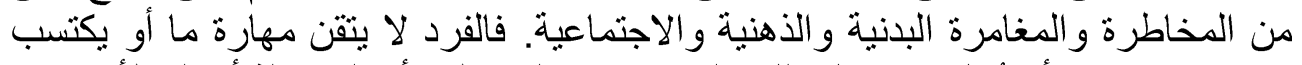

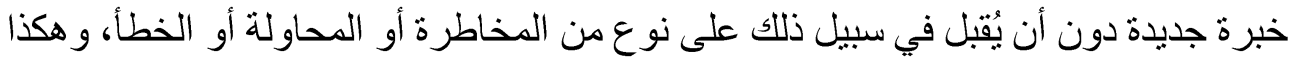

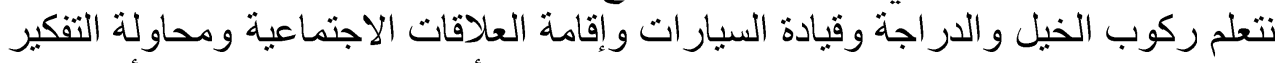

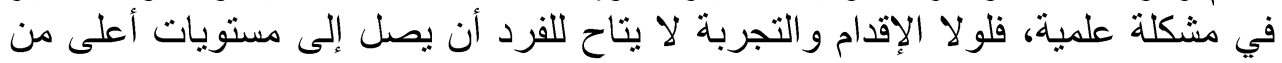

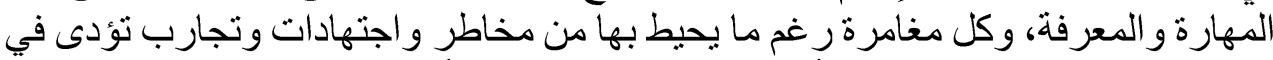

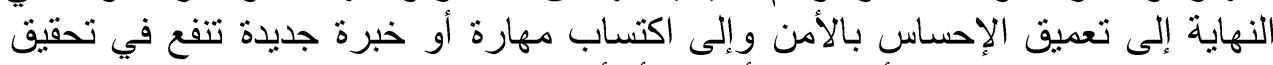

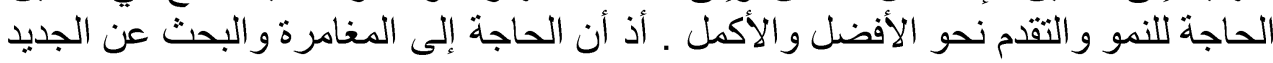

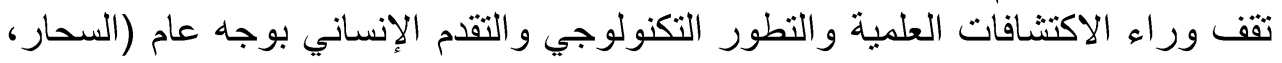

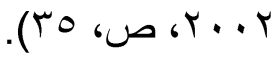

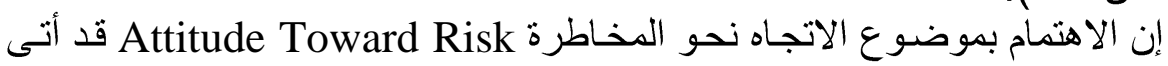

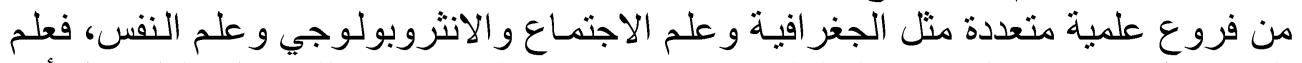

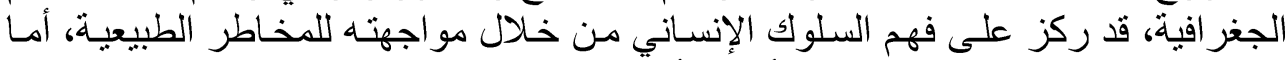

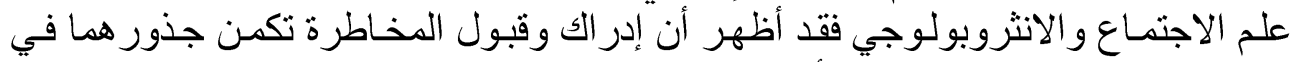

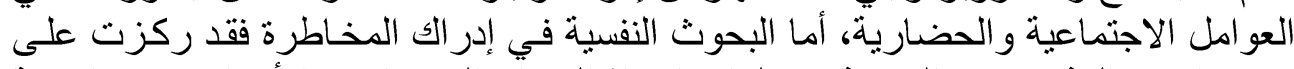

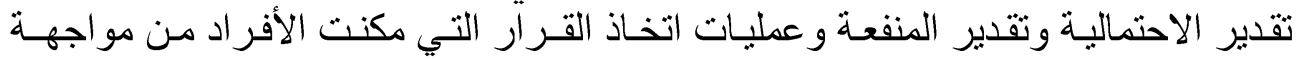

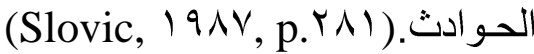

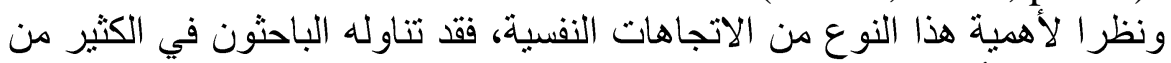

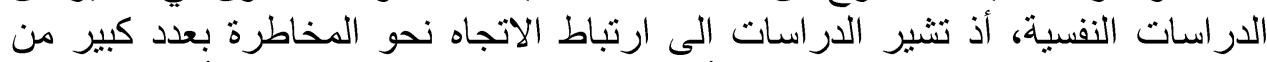

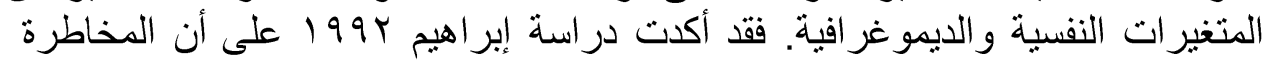

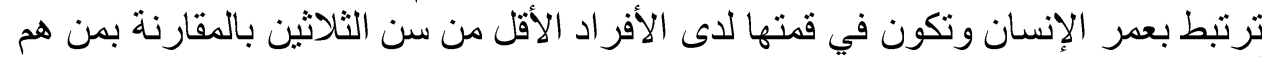

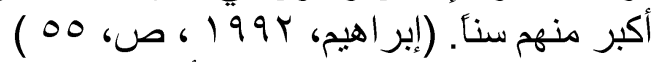

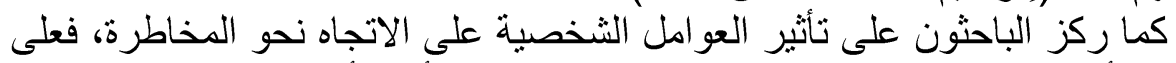

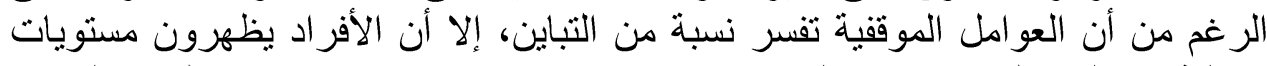

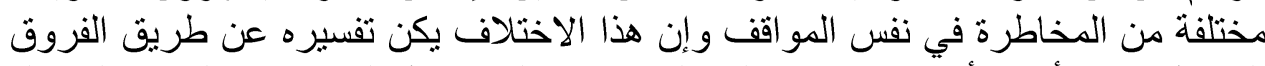

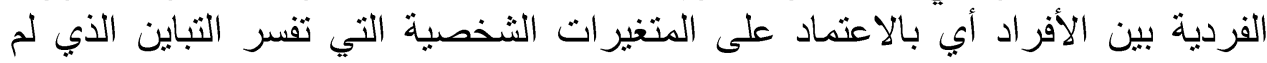

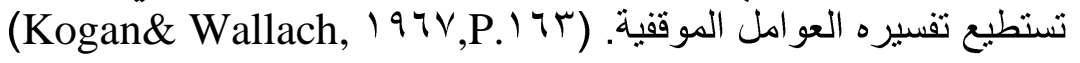


ولا تؤدي الخصائص الثخصية للفرد بمفردها الدور الفعال في مستوى المخـاطرة،

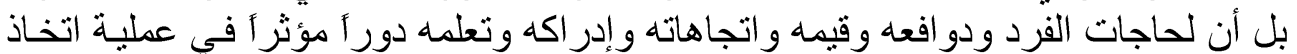

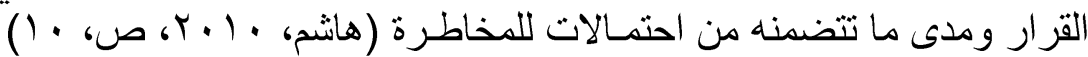

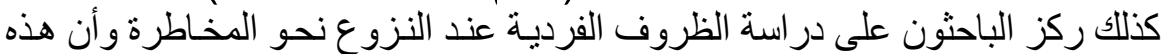

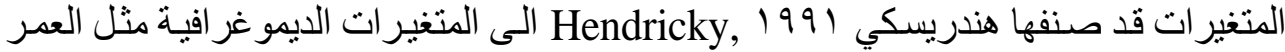

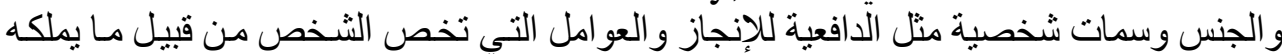
القرد من الخبرة بخصوص مهمة معينة.

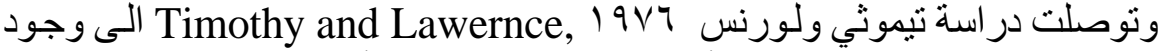

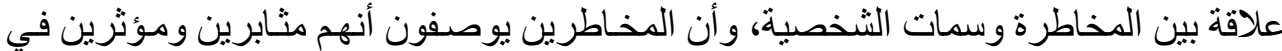

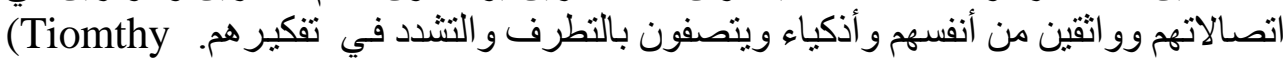

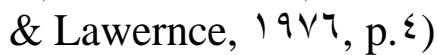

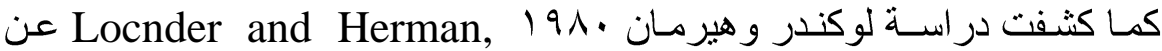

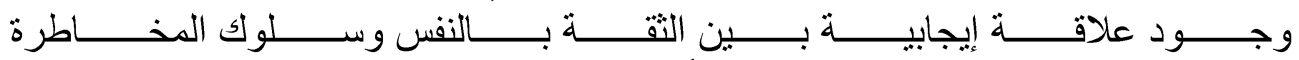

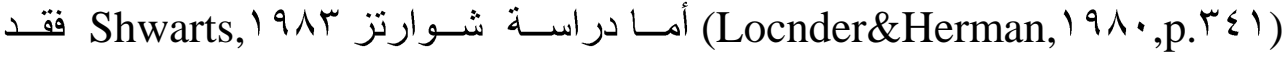

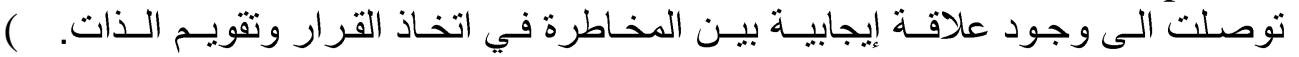
Shwarts, $191 \mathrm{r}, \mathrm{p}$, sor)

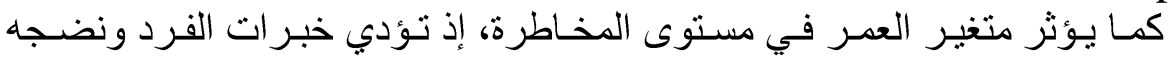

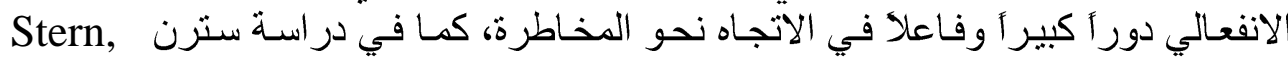

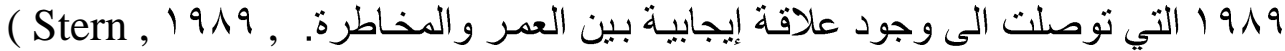

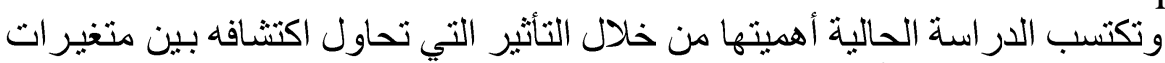

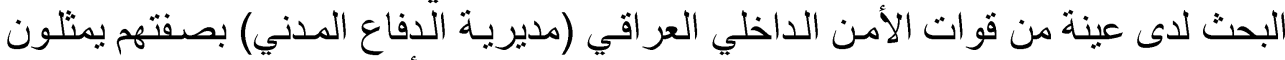

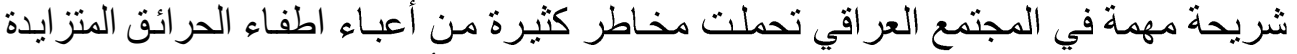

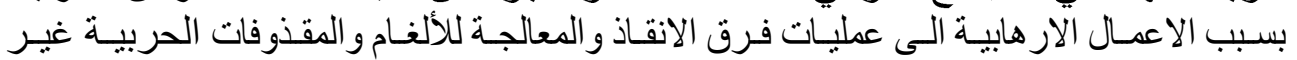

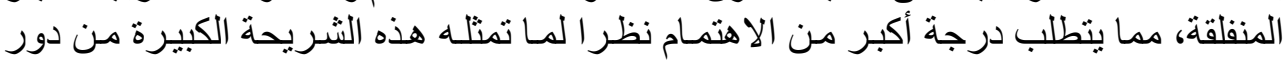

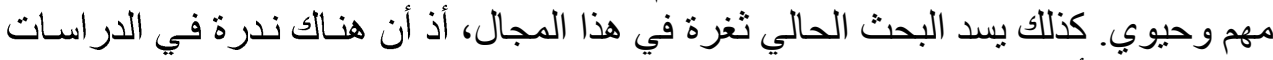

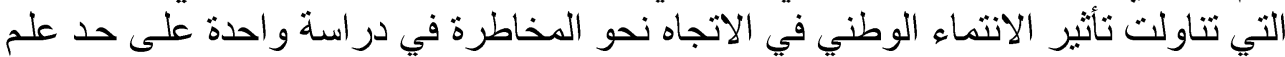

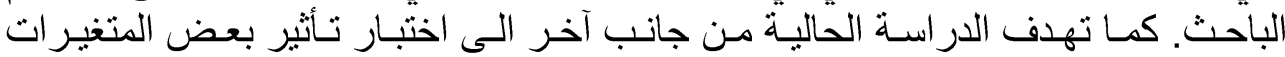

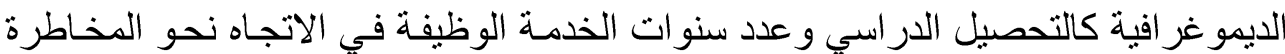

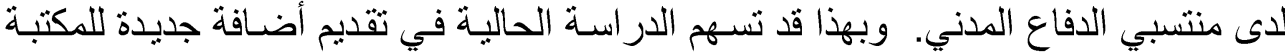

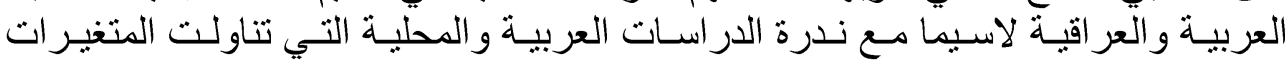

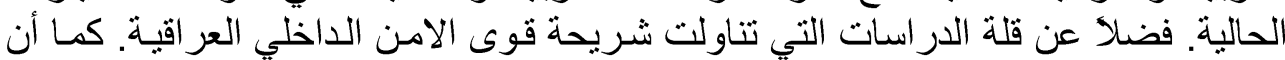

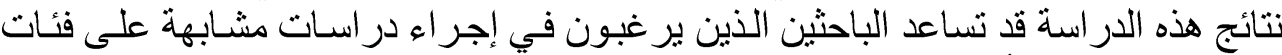

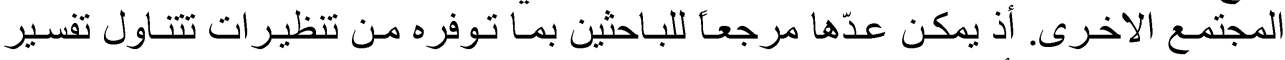

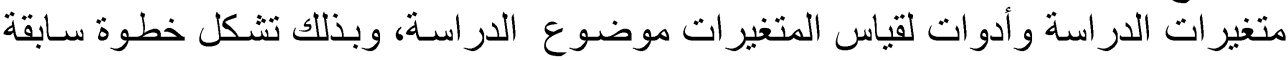
تسهل إجر اء در اسات الاحقة أدوات في هذا الميدان.

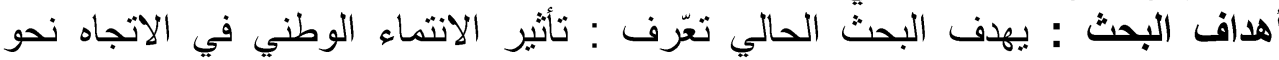
المخاطرة لدى منتسبي الدفاع المدني، من خلال الهن التبار الفرضيات الآتية : ا ـ. يؤثر الانتماء الوطني في الاتجاه نحو المخاطرة. 
r ب. بؤثر التحصيل الدراسي في الاتجاه نحو المخاطرة.

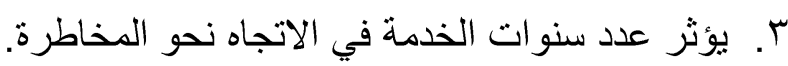
ع. يؤثر التقاعل بين الانتماء الوطني والتحصيل والتو وعدد سنوات الخدمة في الاتجاه نحو المخاطرة.

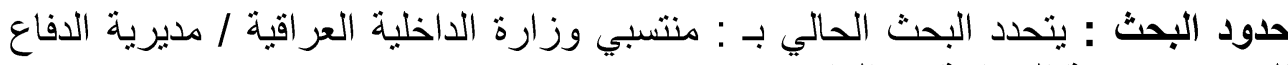

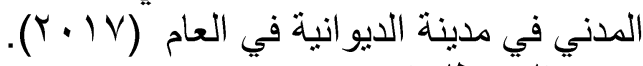
تحديا المصطلحات :

National Affiliation : الانتماء الوطني : • عرفه اريك فروم (Fromm, (941) : حاجة ضرورية للإنسان ليرتفع فوق الطابع

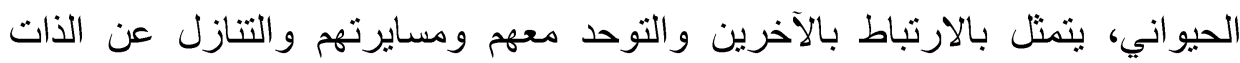

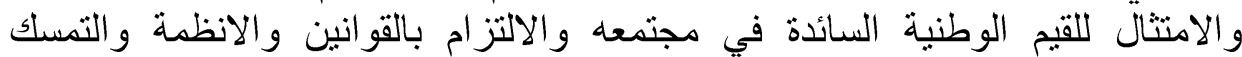

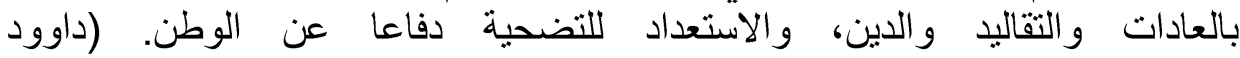

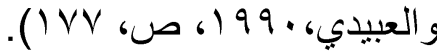
• التعريف النظري : تنبى الباحث تعريف فروم (Fromm,197^) نعريفأ نظريأ لبحثه، وذلك لاعتماده نظريته في قياس الانتماء الوطني. • التعريف الإجرائي : الدرجة الكلية التي يحصل عليها المستجيب في مقياس الانتماء الوطني الني قام الباحث

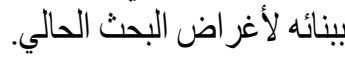

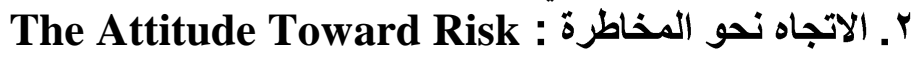

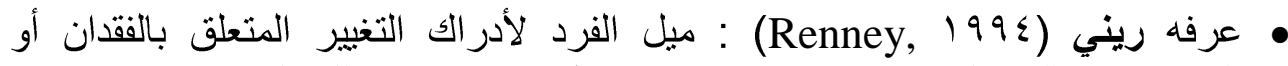

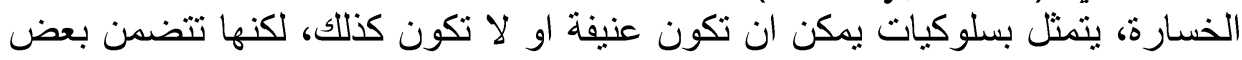

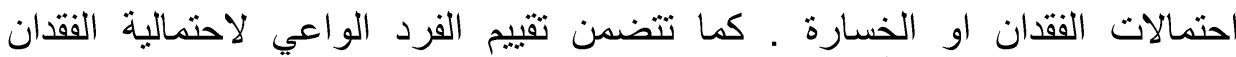

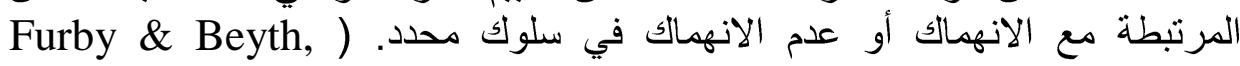
(Marom, $199 \varepsilon$

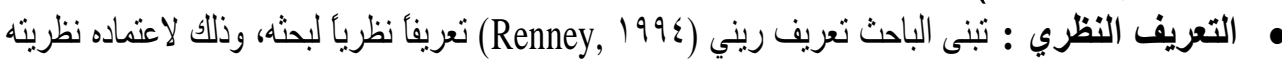
في قياس الاتجاه نحو المخاطرة.

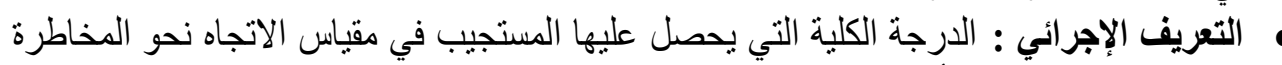

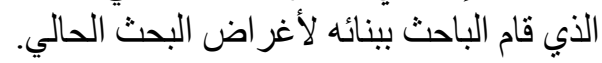

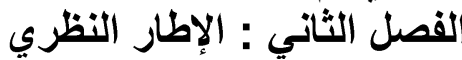

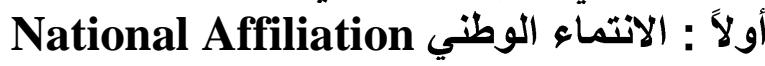

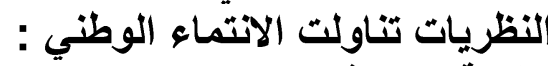

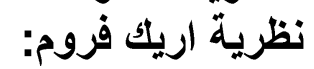

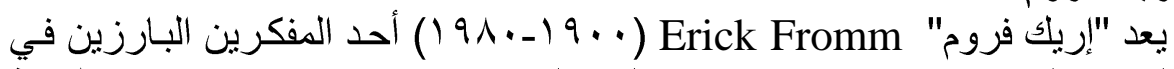

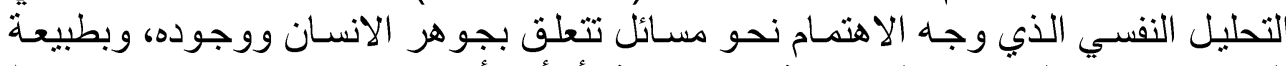

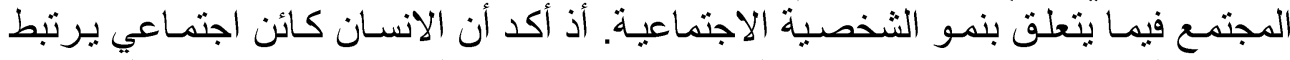

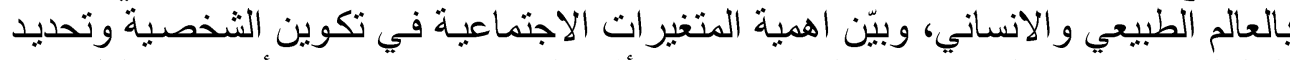

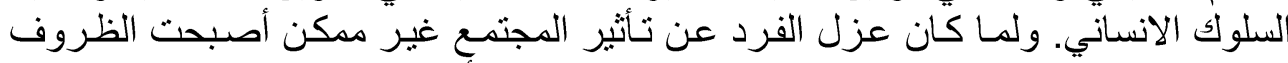

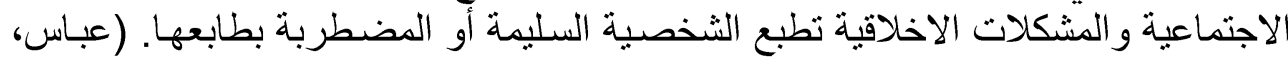




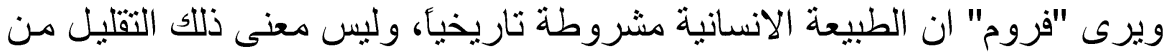

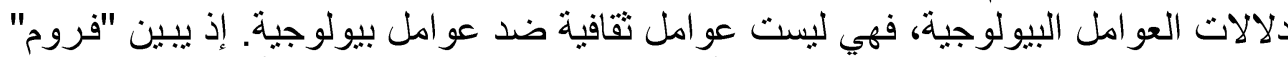

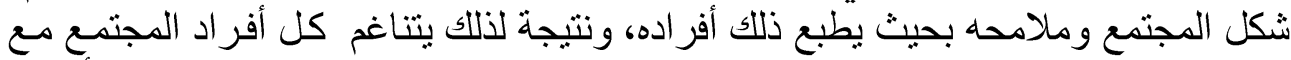

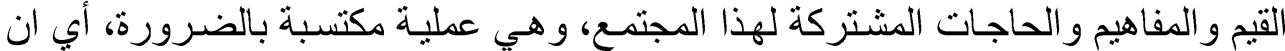

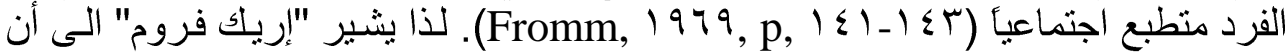

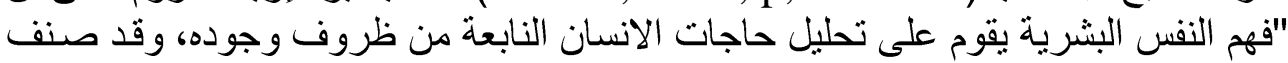

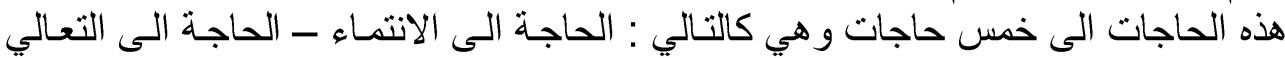

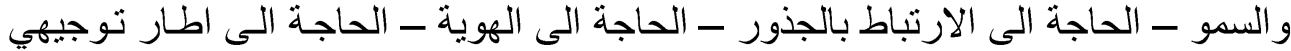

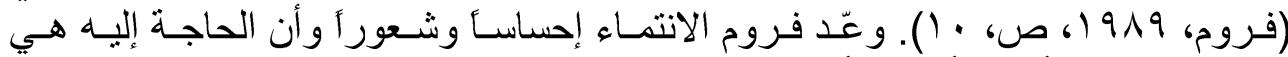

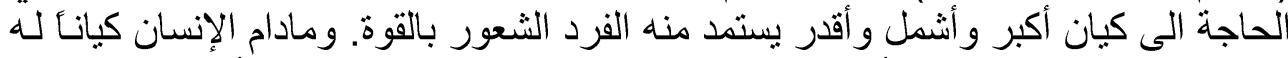

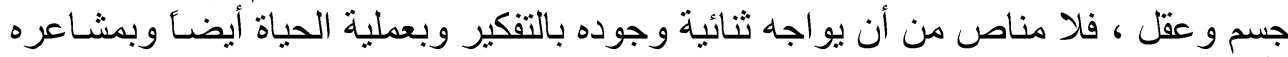

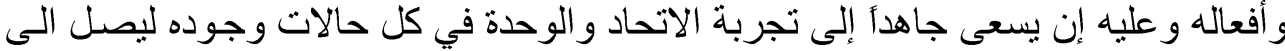

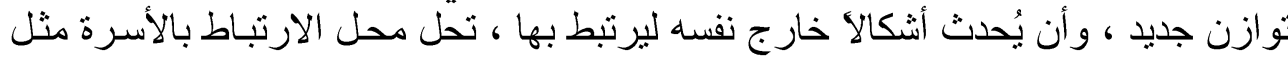

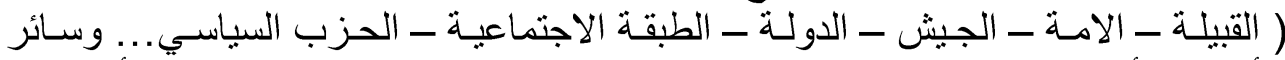

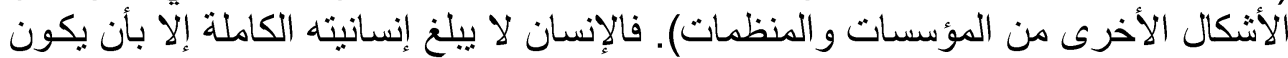

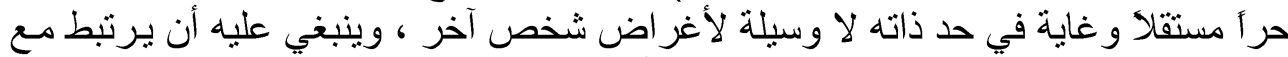

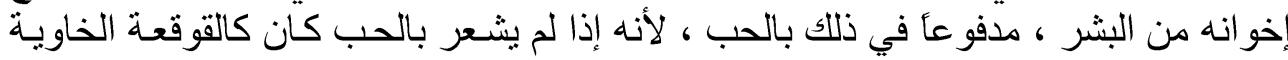

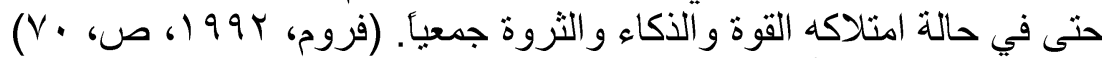

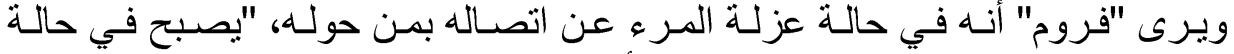
انفصال عن وجوده و غريباً عن نفسه وذاته ، لأنه لبس صانعا لعال لعالمه و ولا يستطيع التحكم فيه

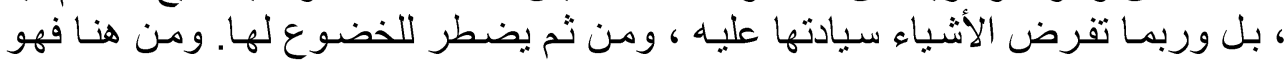
غريب عنها مفتقد لهويته ويعاني من قسوة الوحدة و الاغتر اب نتيجة لفقده ذاته و انفصاله الهن عن

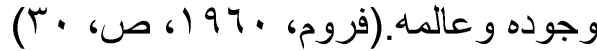

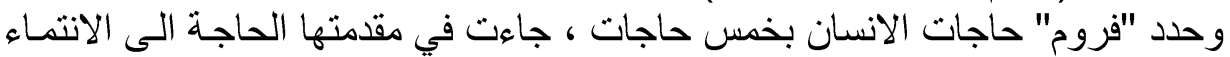

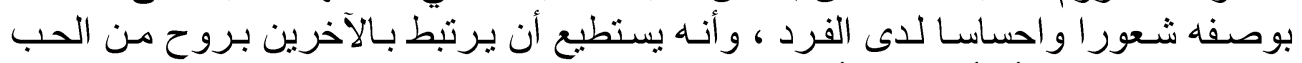

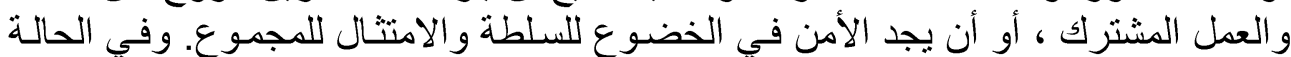

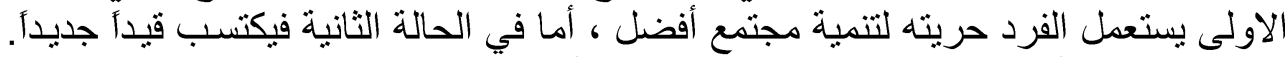

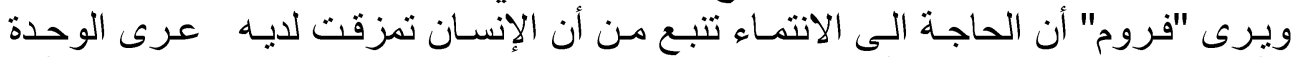

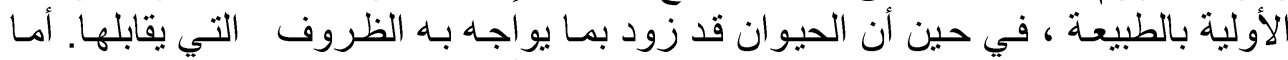

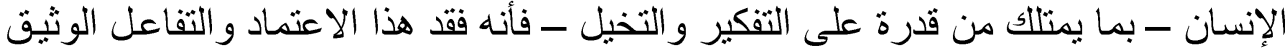

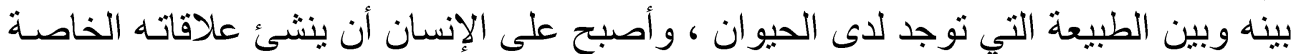

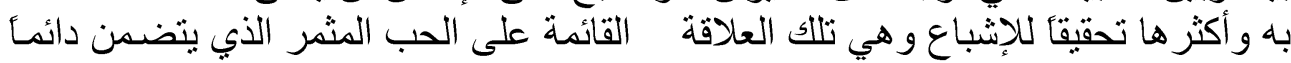

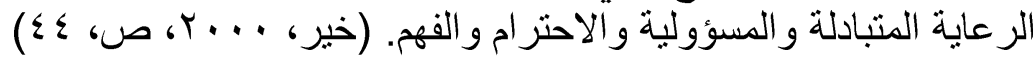

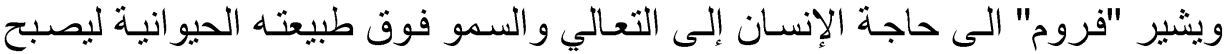

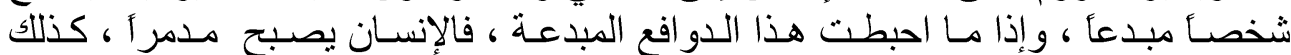

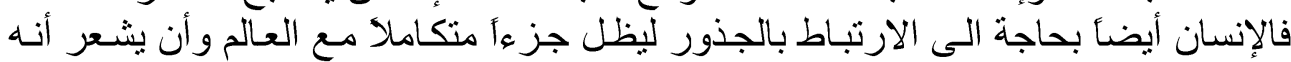

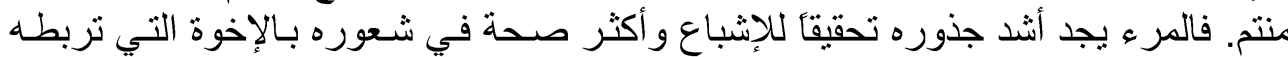

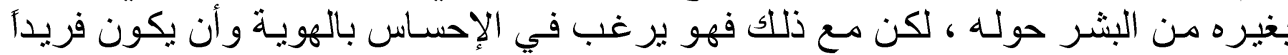

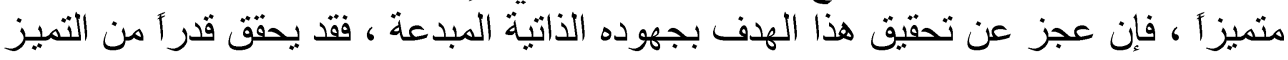


عن طريق التوحد مع شخص آخر أو جماعـة ، فيتوحد المو اطن مع وطنه ويتوحد العامل

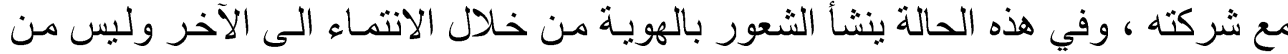

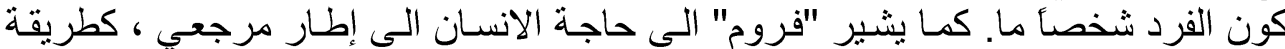

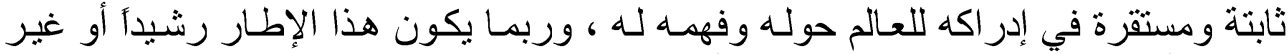

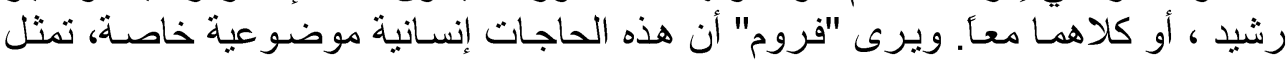

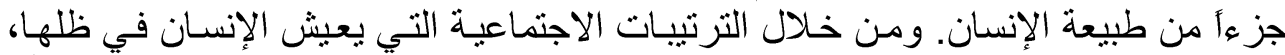

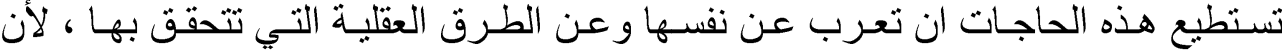

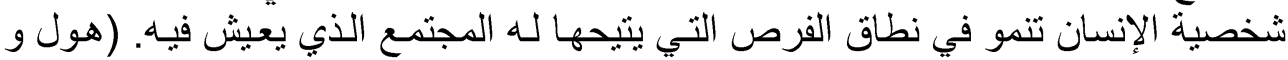

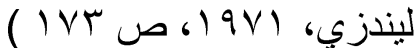
مناقشّة النظرية : لقد عدّ "فروم" الانتماء حاجة أساسية إنسانبة ضرورية لحياة الإنسان ،

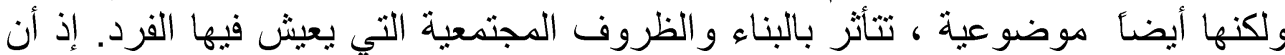

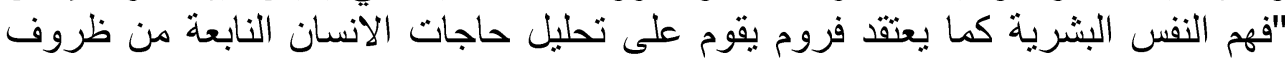

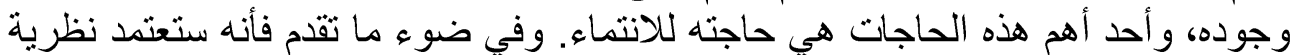

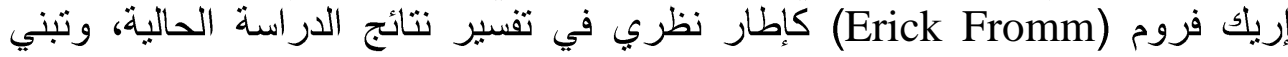

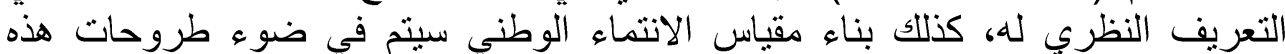

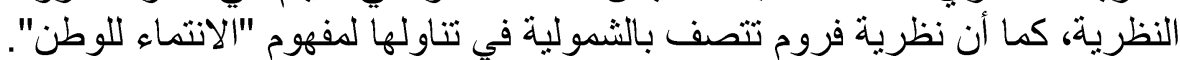
تثانياً : الاتجاه نحو المخاطرة النظريات تناولت الاتجاه نحو المخاطرة :

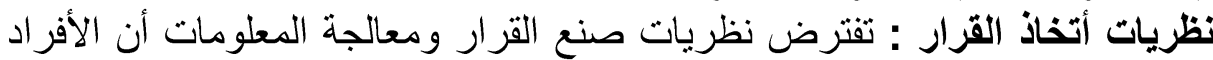

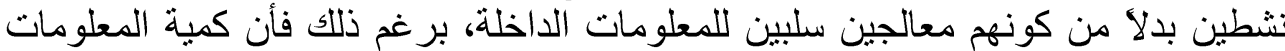

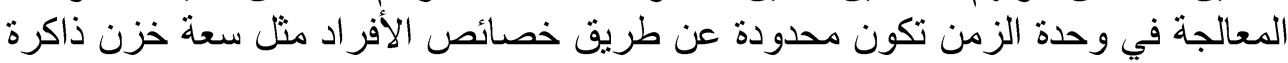

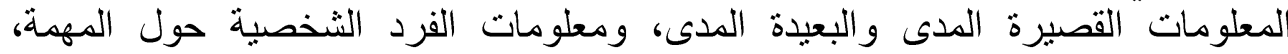

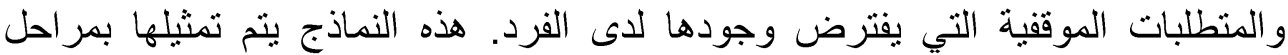

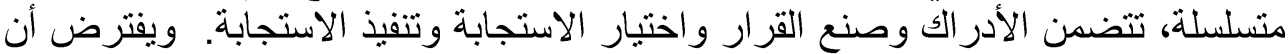

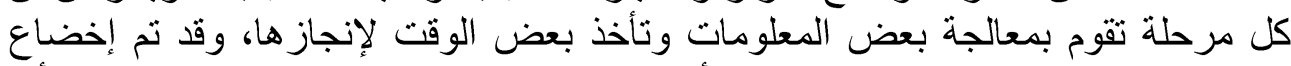

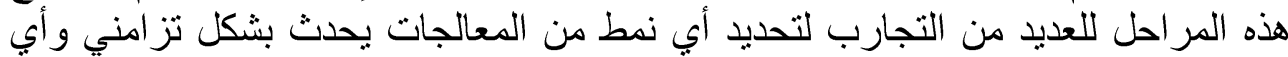
منها يحدث بشكل تسلسلي (Renney, 199 \&, p. VTO . فقد تم تقديم مفهوم التلقائية

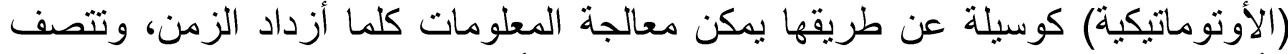

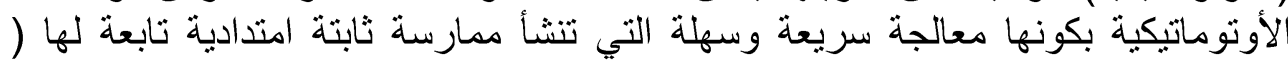

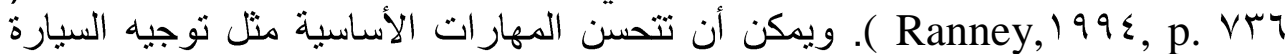
وإيقافها من خلال ترك المصادر المعرفية الأخرى الملائمة لمعالجة مواقف اقف غير الفير مستقرة

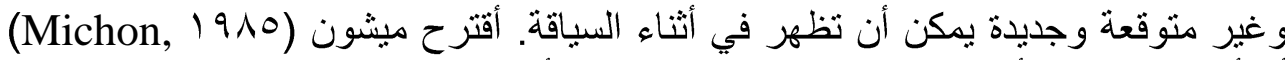

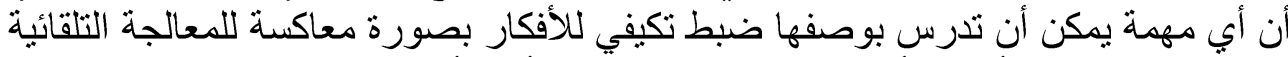
المتعلقة بالسلوك، وأقترح أن الاستناد على المبادئ أو الأنظمة الإنتاجية يمكن استعمالها

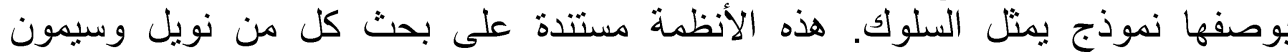

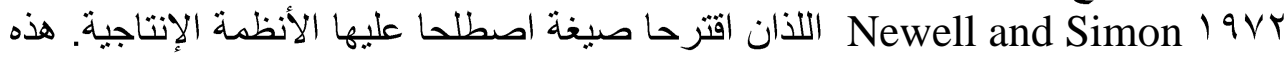

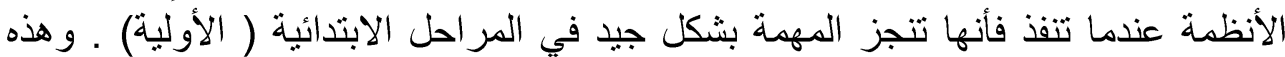

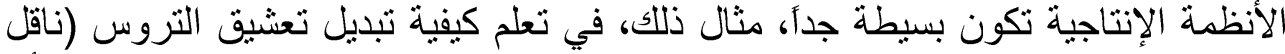

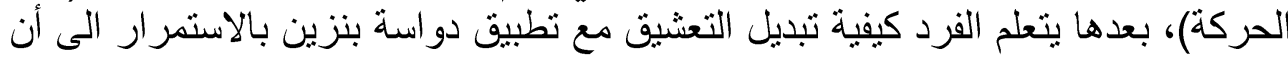


يصل الى السرعة المطلوبة وهكذا تصبح هذه العمليات عادة وتحدث مع قليل من الانتباه.

(Newell \& Simon, 19Vr, p. Y7) مناقشة النظريات: أكدت النظريات المستندة على الزمن، كنظرية التوازن النفسي للخطر،

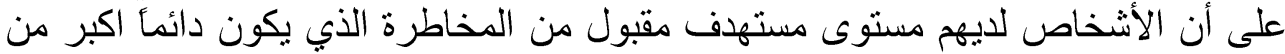

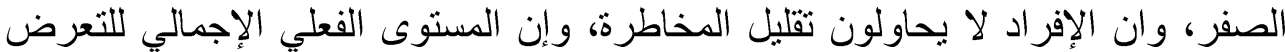

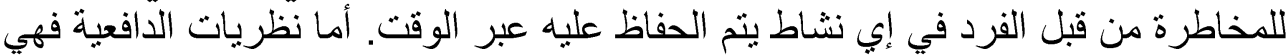

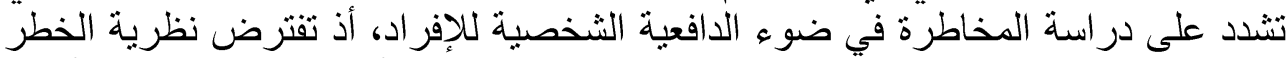

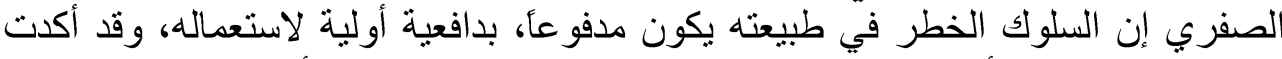

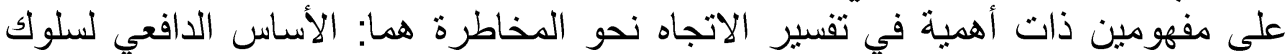

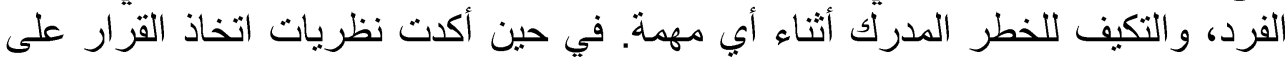

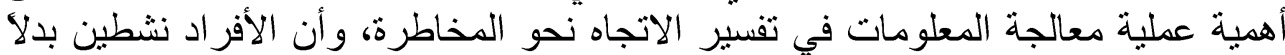

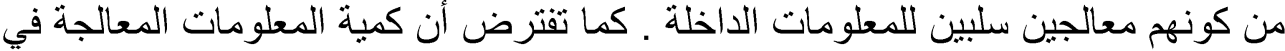

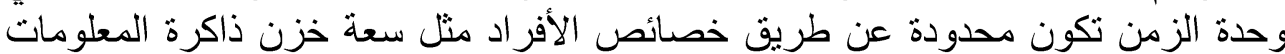

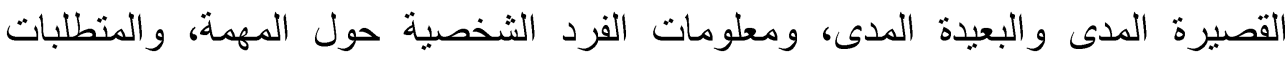

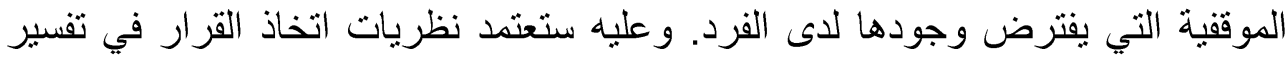

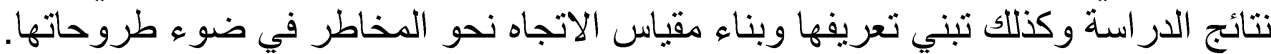

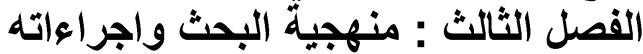

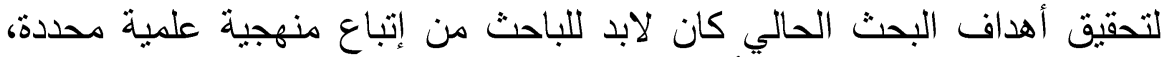

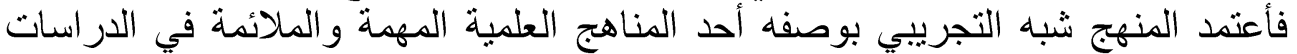

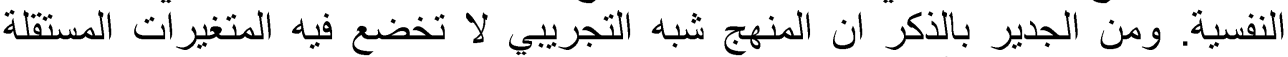

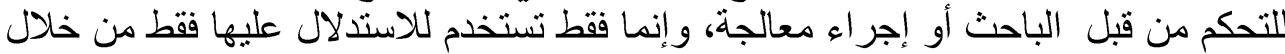

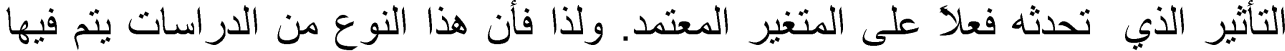

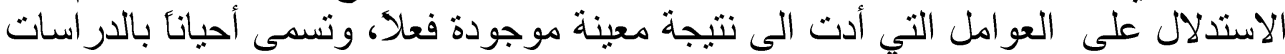

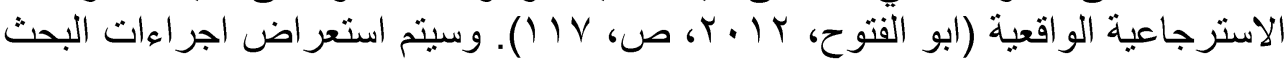

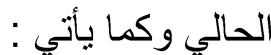

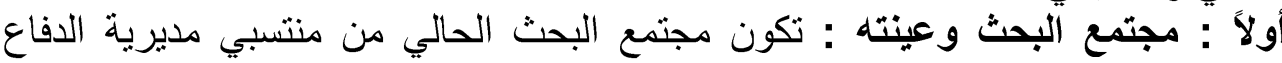

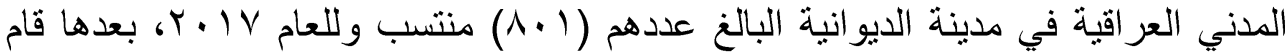

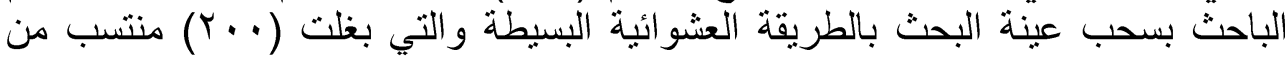
كافة مر اكز مديرية الدفاع المدني في مدينة الديو النية.

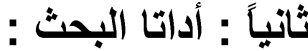

\section{• الأداة الأولى : الاتصاء : الأتماء الوطني}

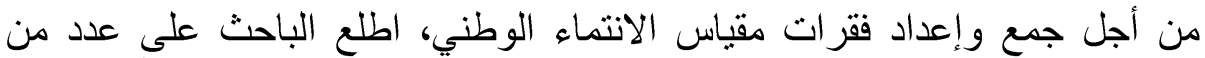

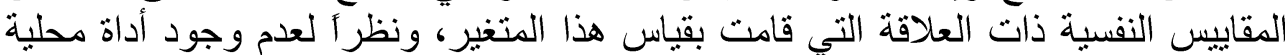

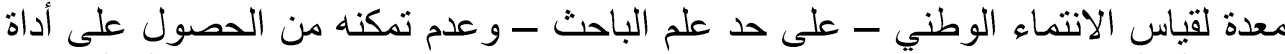

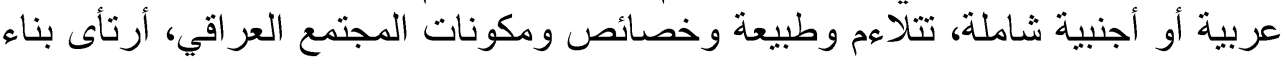

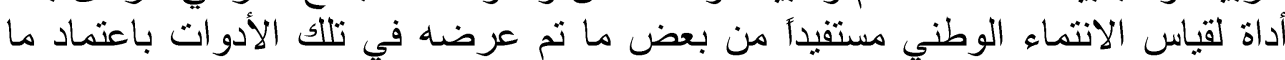

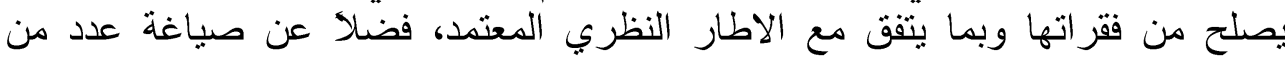

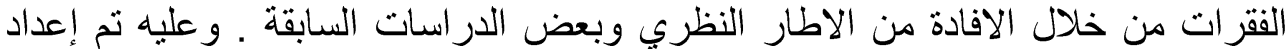
(؟ץ) فقرة لقياس الانتماء الوطني لدى منتسبي الدفاع المدني في مدينة الديوانية تكون 


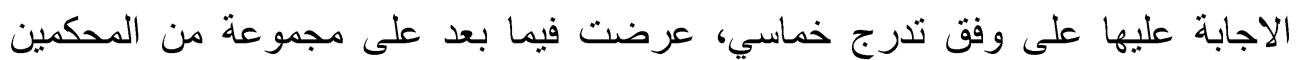

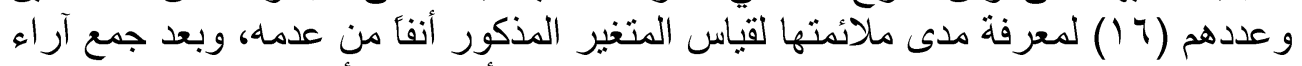

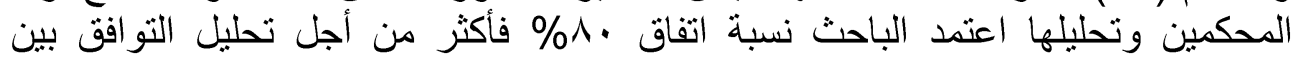

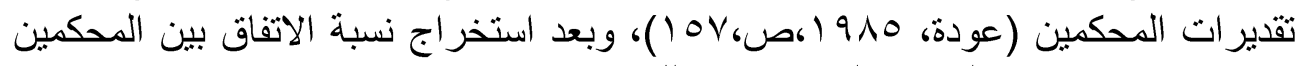

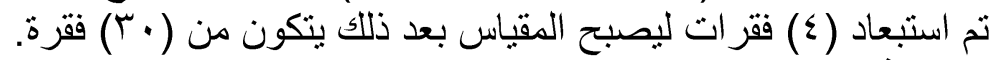

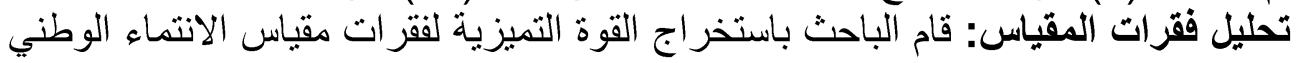

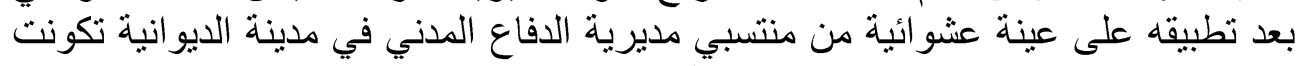

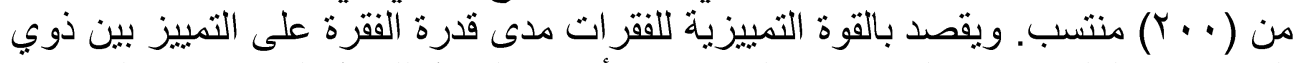

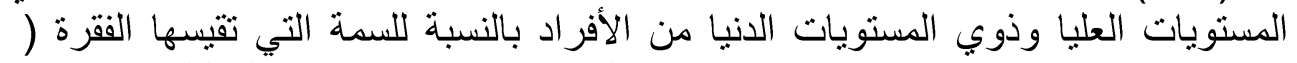

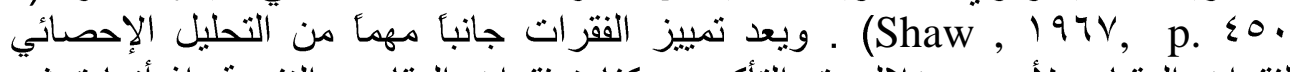

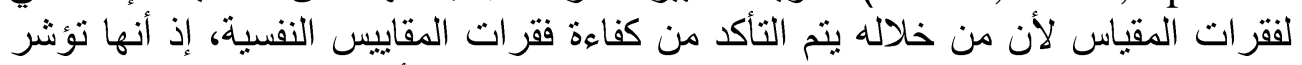

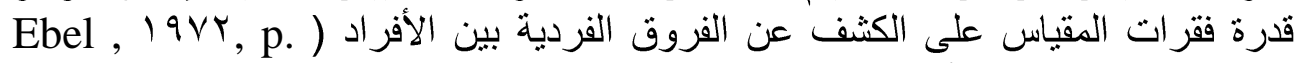

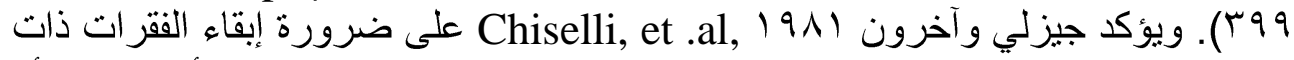

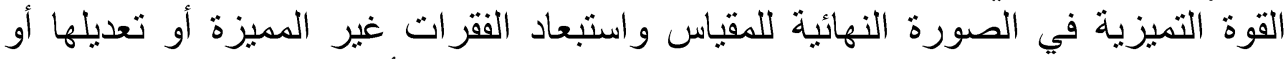

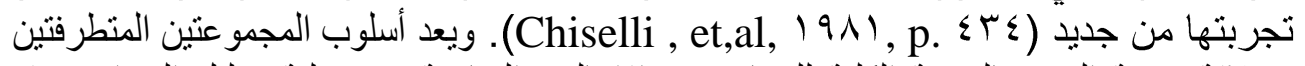

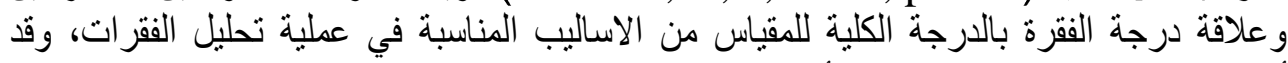

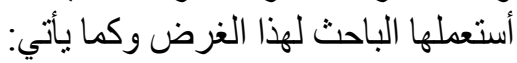

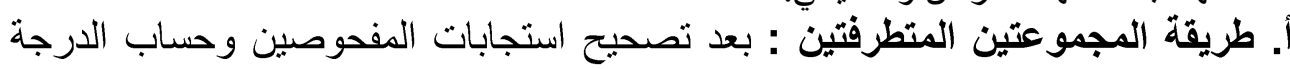

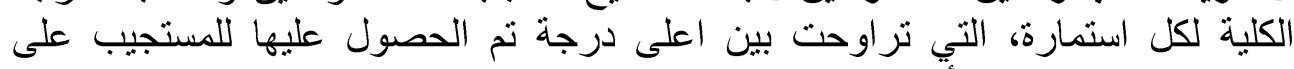

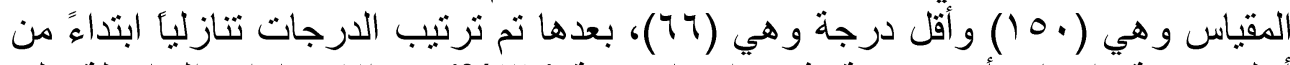

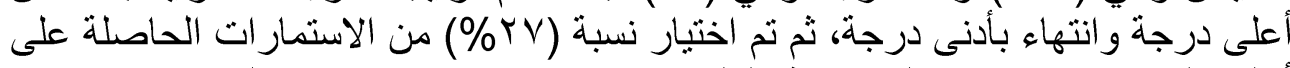

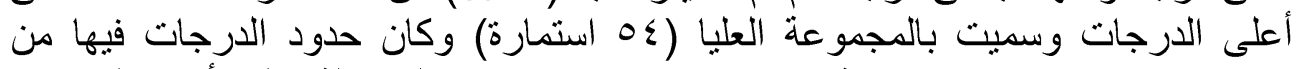

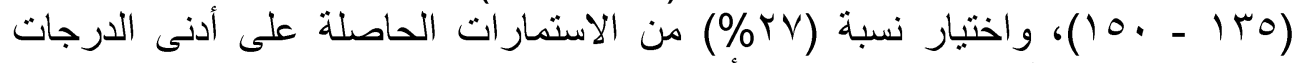

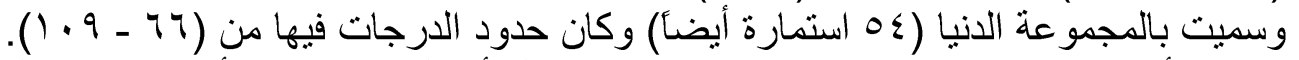

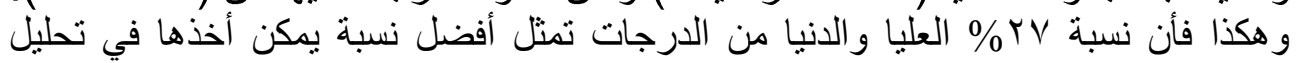

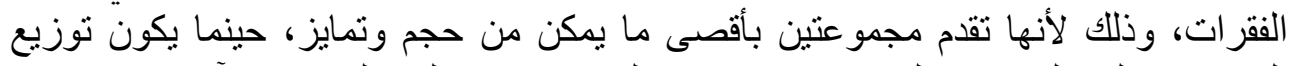

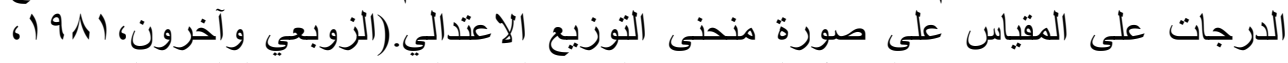

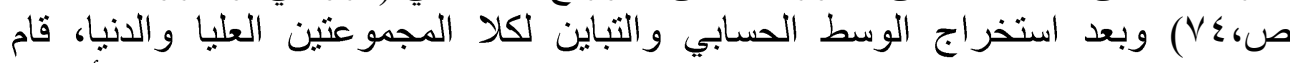

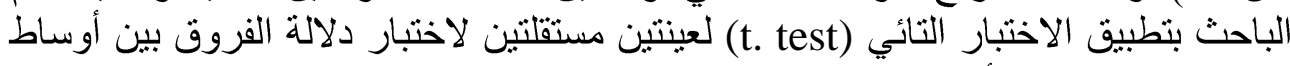

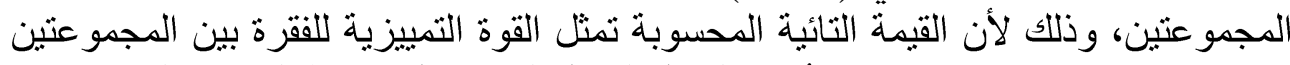

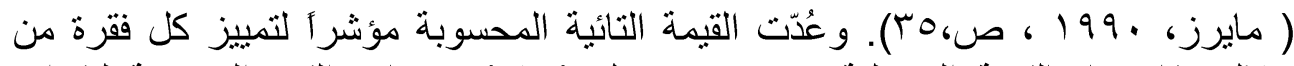

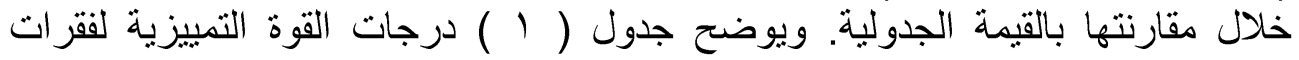
مقياس الانتماء الوطني بطريقة المجمو عتين المتهة المتطر فتين.

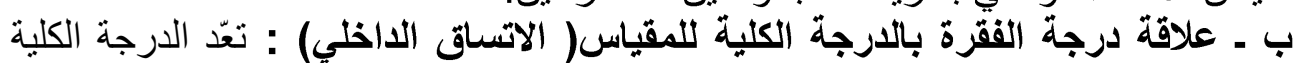

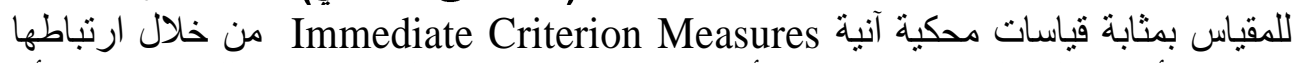

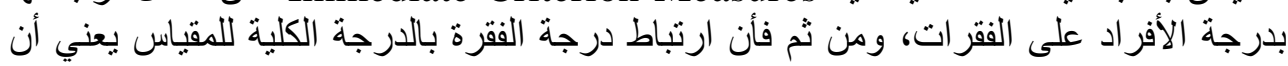

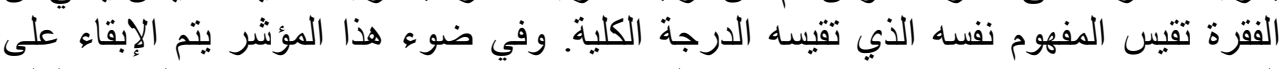

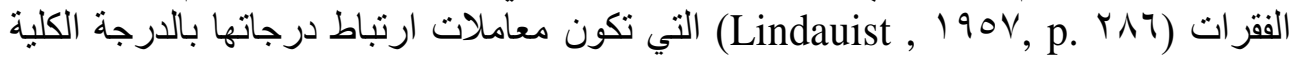

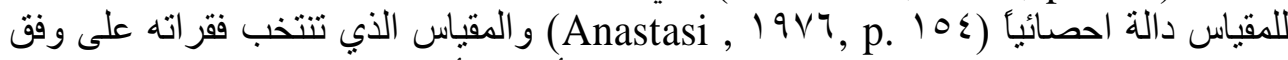

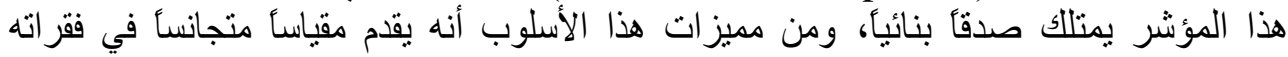
(Pearson Product- Moment وقد استعمل معامل ارتباط بيرسون النهاب (Smith, 1977, p.V•) 
Correlation)

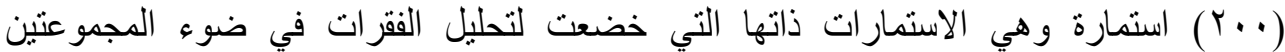

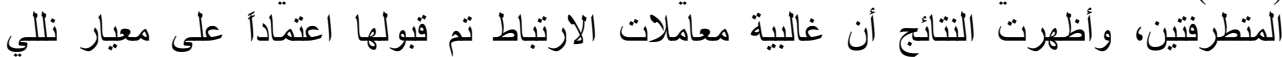

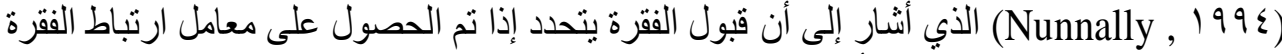

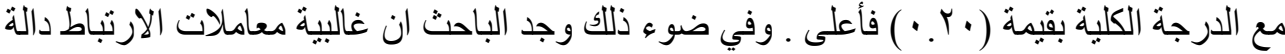
احصائيا وفق هذا المعيار ـ والجدول رقم ( 1 ) يوضح معاملات ارتباط بيرسون بين درجة الفقرة الإنة

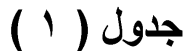

و الارجة الكلية لمقياس الانتماء الوطني.

القوة التمييزية لققرات مقياس الانتماء الوطني بطريقة المجموعتين المتطرفتين وعلاقة

درجة الققرة بالأرجة الكلية

\begin{tabular}{|c|c|c|c|c|c|c|c|}
\hline \multirow[b]{2}{*}{ النتيجة } & \multirow[b]{2}{*}{ قيمة معامل بيرنباط } & \multirow[b]{2}{*}{ المحسوبة القيمة } & \multicolumn{2}{|c|}{ المجمو عة الدنيا } & \multicolumn{2}{|c|}{ المجموعة العليا } & \multirow[b]{2}{*}{ رقةم } \\
\hline & & & الالمعراف & الحسابي الوسط & الالمعياري & الحسابي الوسط & \\
\hline غير دالة & .104 & $1.0 \leqslant r$ & $1 . r 001 \mathrm{~V}$ & 8.1111 & $.9910 . \leq$ & $\varepsilon . \leqslant 7 \%$. & 1 \\
\hline دالة &.$r \Delta \Lambda$ & $\leqslant .9 \vee 0$ & $.019 V$. & $\leqslant .7 \leqslant 11$ & $\ldots \ldots$ & $0 . .$. & $r$ \\
\hline دالة &..$\leqslant$ & 5.00 &.$\wedge r \Delta q 0$ & $\leqslant . \leqslant . V \leqslant$ & . YMIYI & $\leq .9 \leq \leqslant \leq$ & $r$ \\
\hline دالة &.$r \Delta r$ & 0.791 & & $5.57 \%$ & $\because \cdots$ & $0 \ldots$ & $\varepsilon$ \\
\hline دالة & $. r \leq \leq$ & $r . r \Lambda$ & $1 . r 001 \mathrm{~V}$ & $r . \wedge \wedge \wedge q$ & $.97 r 0 r$ & $\leq .0 V \leq 1$ & 0 \\
\hline دالة &. .111 & $r . r \leq 0$ & $1 . \leqslant \leq \wedge \wedge \vee$ & $r . v \cdot r v$ & $.9 .0 \vee 7$ & $\leq . \leqslant 10$ & 7 \\
\hline دالة &..$\leqslant \wedge 4$ & O.YYY & $1.17 \leq 7$ & $E . r \cdot r V$ & . YMIYI & $\leq .9 \leq \leq \leq$ & $\mathrm{V}$ \\
\hline دالة &..$\leqslant Y V$ & $0.7 V 7$ & 1.THYE & $r . \leqslant r \Delta q$ & $. . \leqslant \wedge \mu \mid r$ & $\varepsilon . V \leq \cdot V$ & $\Lambda$ \\
\hline دالة &. $.7 V T$ & $10 . r+1$ & I.YKYVI & $1.9 . v \leq$ & $.7947 \leq$ & S.AKrr & 9 \\
\hline دالة &. .517 & $0 . \Lambda \cdot r$ & $1.1 \leq 94 \leq$ & 1.7978 & $1.0 V \cdot V r$ & r.Y.rV & 1. \\
\hline دالة & $\because Y O \leq$ & 4.17. & 1.0900 & $£ .0 \ldots$ &. .19 .74 & ะ.974. & 11 \\
\hline دالة &.$V \ldots$ & $4 . .91 \leq$ & .90174 & 1.7778 &..$O V \vee \wedge V$ & 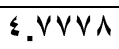 & Ir \\
\hline دالة & $.7 \pi$ & $10.0 \mathrm{Vr}$ & $.9 \vee 1 Y 9$ & 1.7978 & $1.99 \mathrm{rr}$ & $5.7 Y 97$ & ir \\
\hline دالة &. .199 & $r . \leqslant \wedge 4$ & $1 . r \vee r \wedge r$ & $\varepsilon \ldots$ & . Arryo & E.VYYY & $1 \varepsilon$ \\
\hline دالة & $\cdot r \leqslant 0$ & $r . . \leq 9$ & $1 . r 00 r$ & $\varepsilon . Y \vee \vee \Lambda$ & $\cdot . \vee \vee \wedge \wedge r$ & $\leq . \wedge 1 \leq \Lambda$ & 10 \\
\hline غير دالة &. $.1 \mathrm{rV}$ & I.rrr & E & 1.9110 & $1 . \leqslant r r q q$ & $\varepsilon . r \wedge \wedge q$ & 17 \\
\hline دالة & $.9 V \leq$ & 11.919 & $1.10 \mathrm{VVV}$ & $\varepsilon .+r v$. & $. .1+4.1$ & $\varepsilon .9110$ & iv \\
\hline دالة & $\cdot . r 00$ & $\leq . \wedge \leq r$ & $1 . r 0011$ & r.Arrr &. $.791 \mathrm{rV}$ & 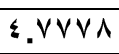 & 11 \\
\hline دالة & 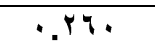 & $0 . r \leqslant r$ & 1.50499 & r.797V &. $.7170 \mathrm{~V}$ & $\leqslant . \wedge 1 \leqslant \Lambda$ & 19 \\
\hline دالة &.$r \Delta r$ & 0.114 & 1.rrATq & $r .9110$ & 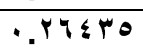 & ะ.qY०q & r. \\
\hline دالة & .074 & 11.971 & 1.1197. & $1.9 \leq \leq \leq$ & $1 .+\ldots \ldots$ & $£ .0004$ & $Y 1$ \\
\hline دالة & $. .54 \leq$ & 9.97 & $1 .+7 \wedge v \leq$ & 5.978 &. .114 .1 & 2.9110 & YY \\
\hline دالة & $\because \leqslant T_{0}$ & $1 \leq .191$ & $.91 \leq \leq$ & 5.4019 & $\because \ldots \ldots$ & $0 . .$. & rr \\
\hline دالة &. .579 & 0.0rr & 1. MOYVY & $r .9 \wedge 10$ & $\ldots \ldots$ & $0 . .$. & $r \varepsilon$ \\
\hline دالة &.$r q V$ & 8.990 & $\because \wedge 9 \wedge 99$ & $\varepsilon . r \wedge \wedge q$ & $\because \cdots \cdots$ & $0 \ldots \ldots$ & ro \\
\hline دالة &. .74. & $1 r .11$. & 1.01 .7 & $1 . \vee \vee \vee \wedge$ & .999710 & $\varepsilon . \mu V . \varepsilon$ & YT \\
\hline دالة & $. r 1 \leq$ & r.94 & $1 . \wedge r \wedge V$ & $\varepsilon .110 r$ & $.090 \wedge r$ & $\varepsilon . \wedge 019$ & YV \\
\hline دالة & .740 & $1 r . \leq \leq 9$ & 1.MOYVY & Y. INo & $. .7 \leq r M A$ & $\Sigma . V \circ 94$ & $r \wedge$ \\
\hline دالة & .704 & $10 . \wedge \mu r$ & 1.1109. & $1.9 .8 \leq$ & $.7 r 0 \wedge 0$ & ะ.V94 & rq \\
\hline
\end{tabular}




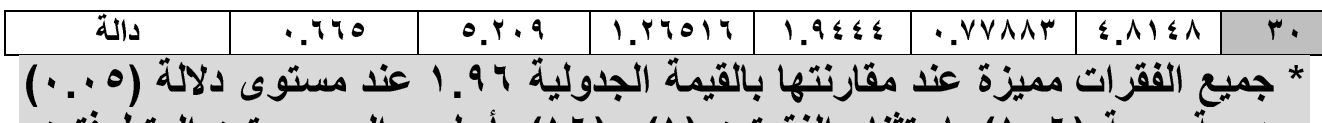

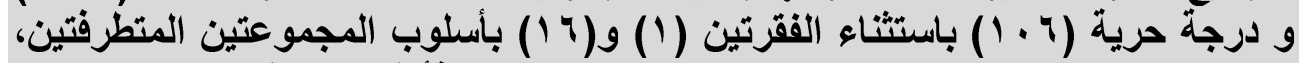

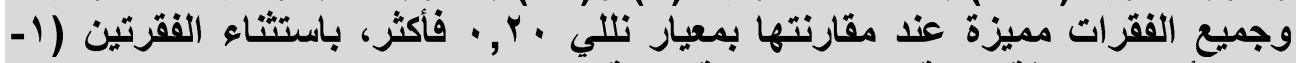

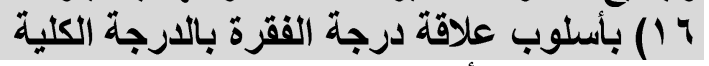

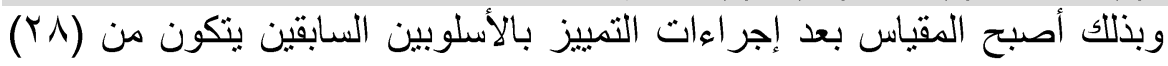

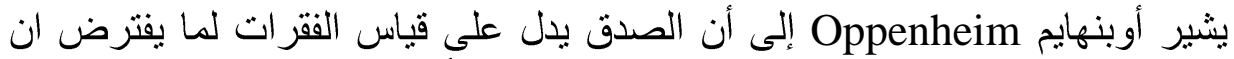

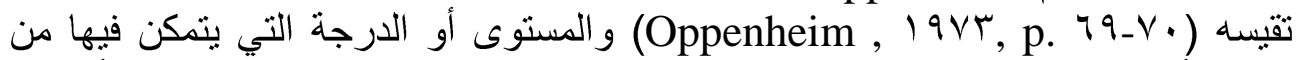

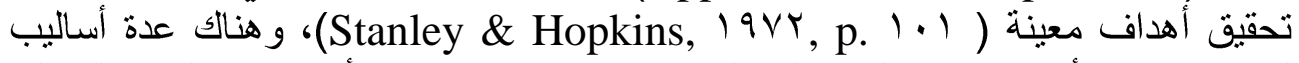

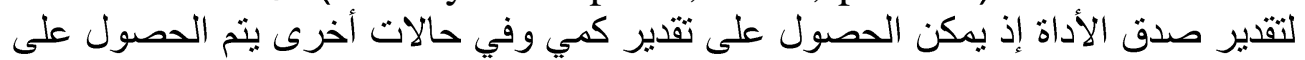

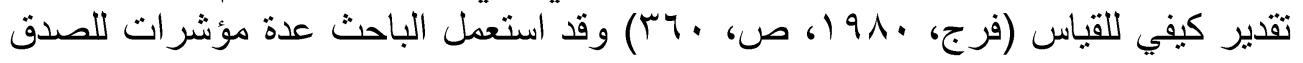
وهي: المنائ أ الّين الظاهري Face Validity : إن أفضل طريقة لحساب الصدق الظاهري هي

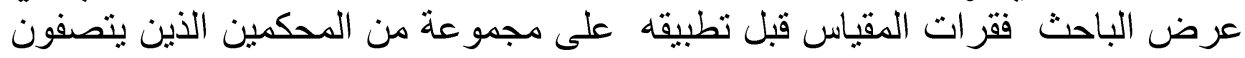

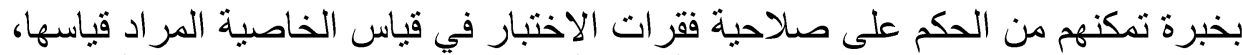

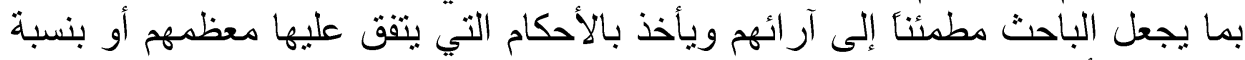

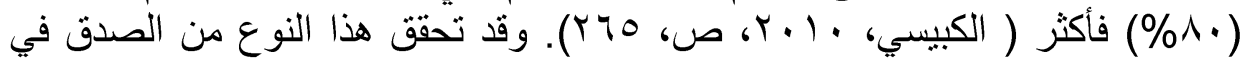
المقياس الحالي وذلك عندما عرضت فقر اته على مجموعة من المحكمين المتخصصين في ميدان علم النفس.

r. صدق البناء Constract Validity : يعد صدق البناء (Constract Validity)

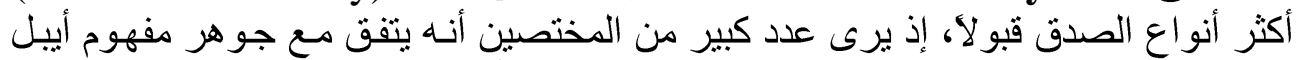
Ebel

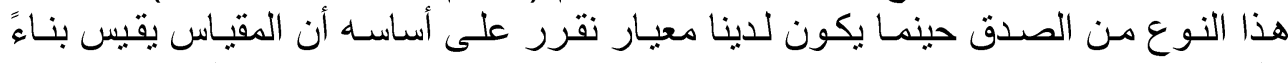

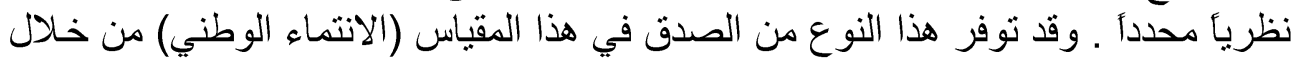
مؤشر ( ارتباط درجة الفقرة بالدرجة الكوان الكلية للمقياس).

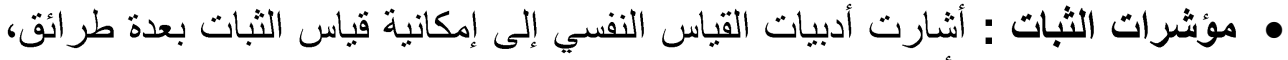

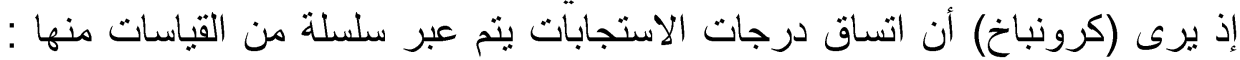

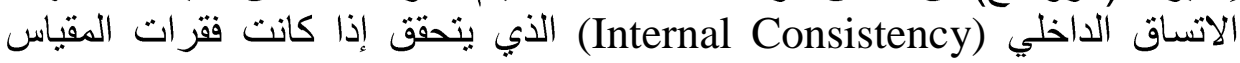

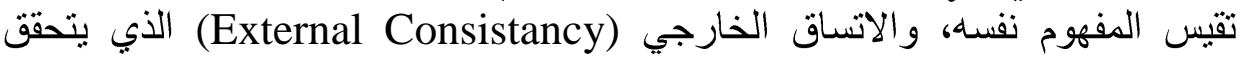
حينما يستمر المقياس في إعطاء النتائج نفسها إذا (إ) ما تمت إعادة تطبيقه عبر مدة زمنية (Holt \& Irving, I9V।, P. I·)

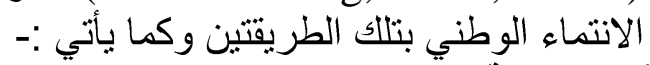

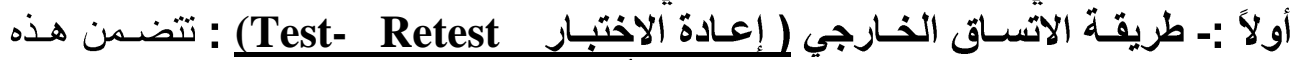

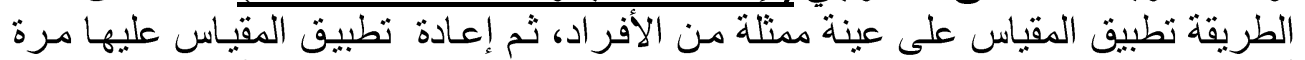

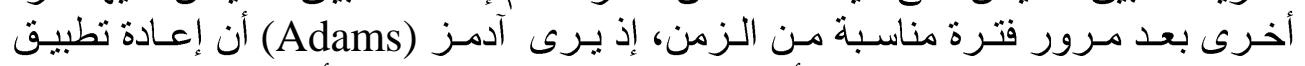

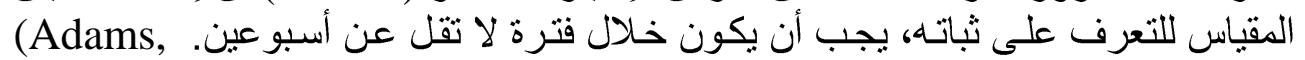
(97 \&, p. 01)

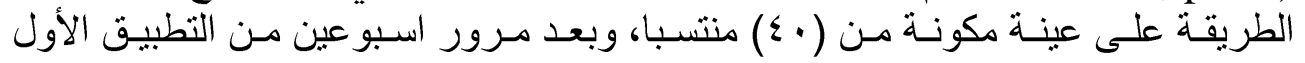


للمقياس قام الباحث بإعادة تطبيق المقياس ذاته مرة أخرى و على العينة ذاتها، وبعد استعمال

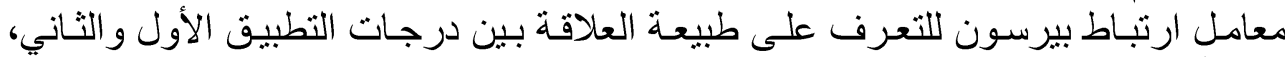

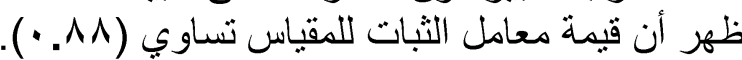

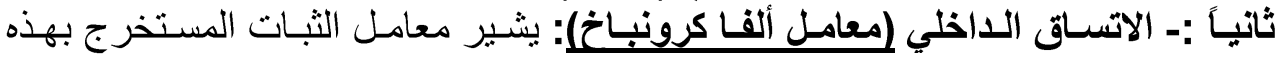

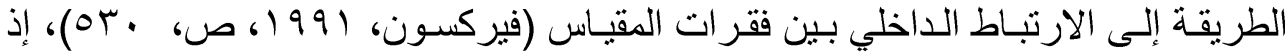

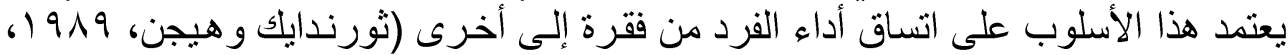

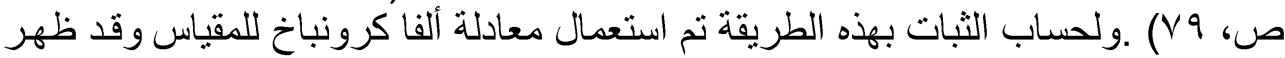

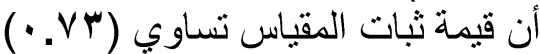

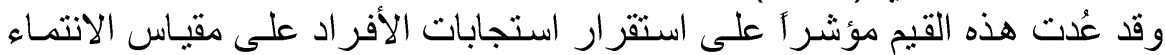

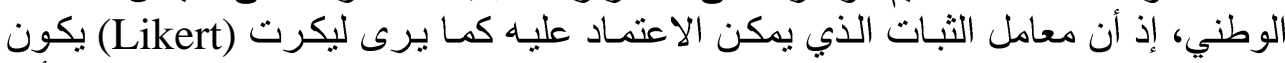

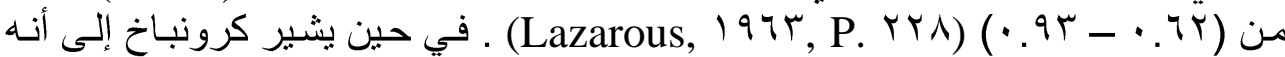

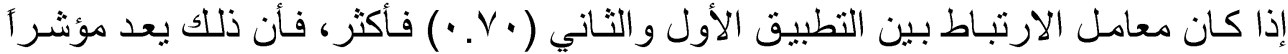

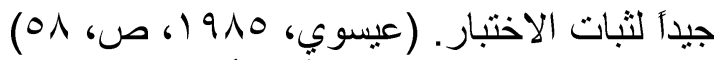

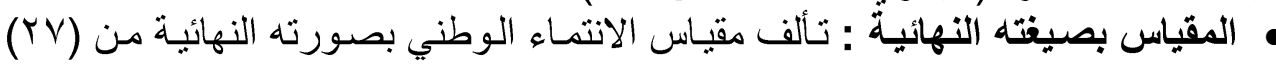

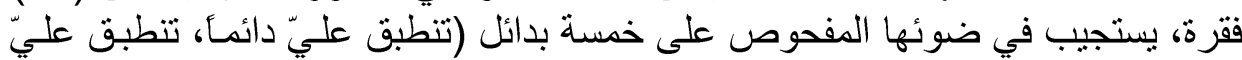

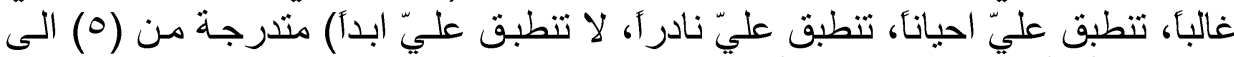

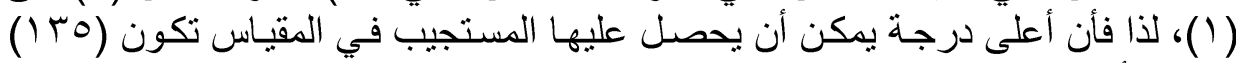

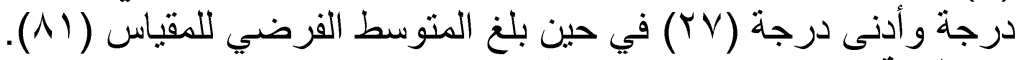

\section{الأداة الثانية : الاتجاه نحو المخاطرة}

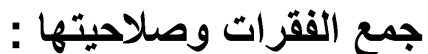

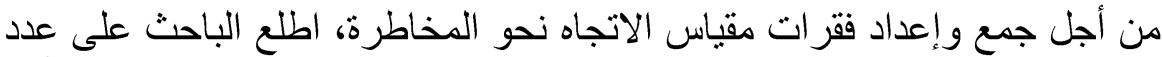

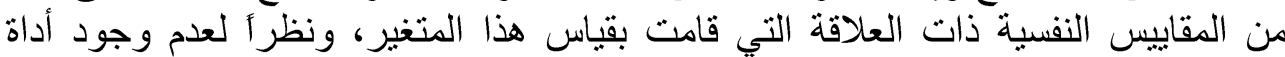
محلية معدة لقياس الاتجاه نحو المخاطرة - على حد على علم الباحث - ـ وعدم تمكنه من

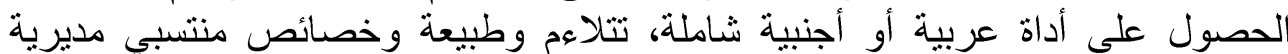

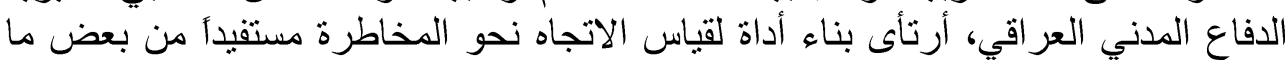

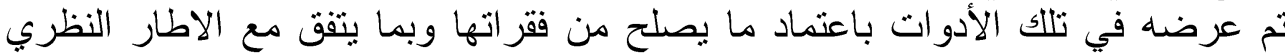

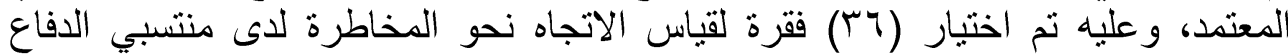

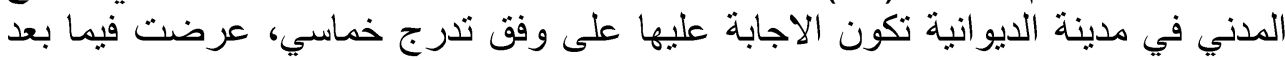

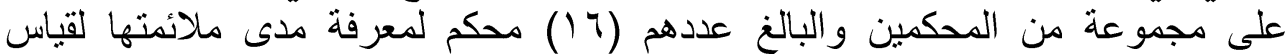

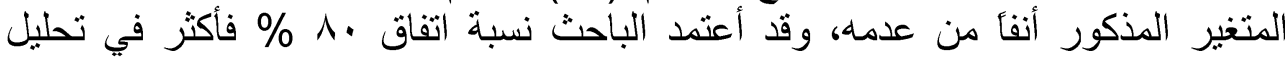

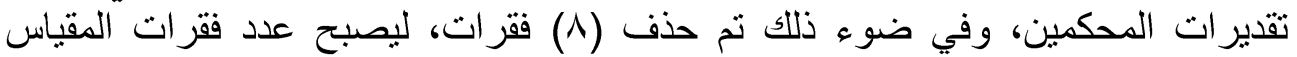

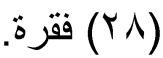
• تحليل الفقرات : قام الباحث باستخراج القوة التميزية لفقرات مقياس الاتجاه نحو

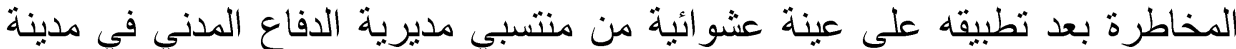

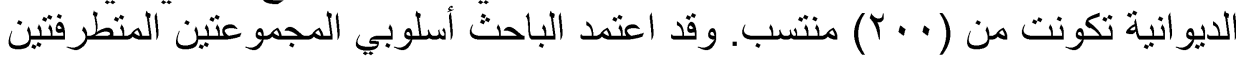
وعلاقة درجة الفقرة بالدرجة الكلية للمقياس في استخر اج القوة التمييزية للققرات التين وكما أ . "الّجموعتين المتطرفتين. Contrasted Groups: بعد تصحيح استجابات

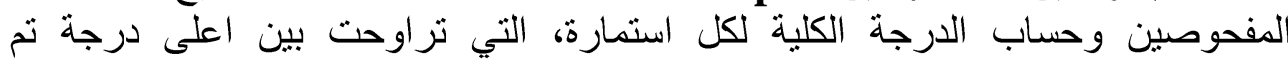




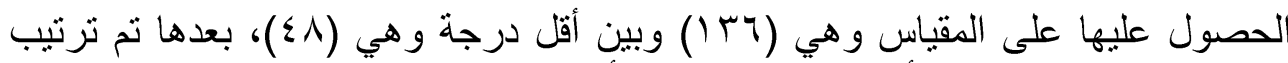

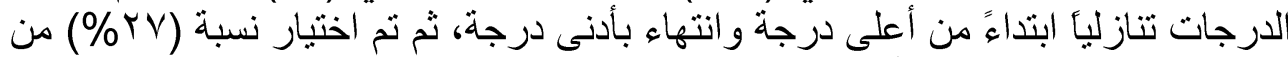

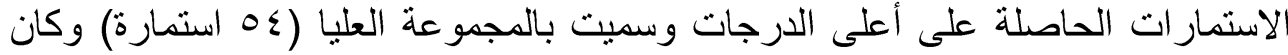

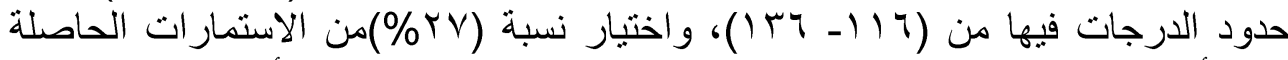

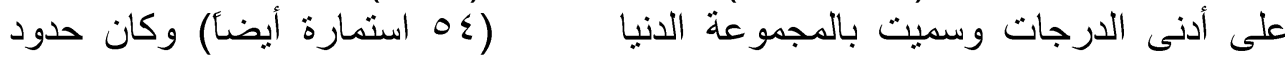

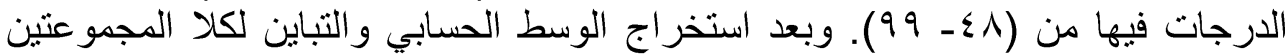

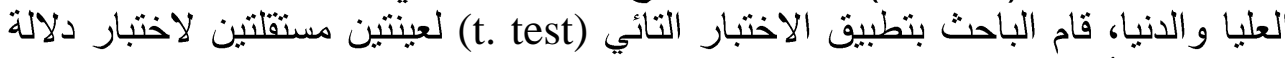

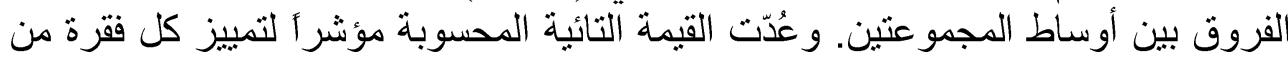

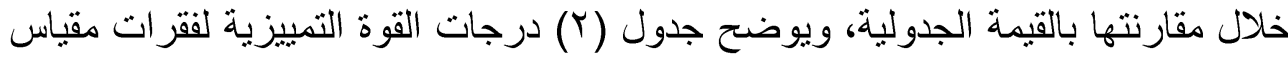

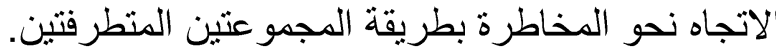

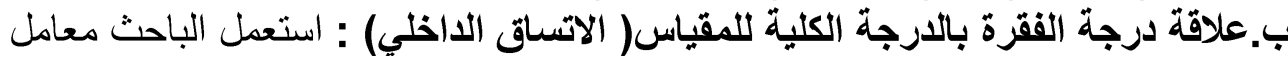

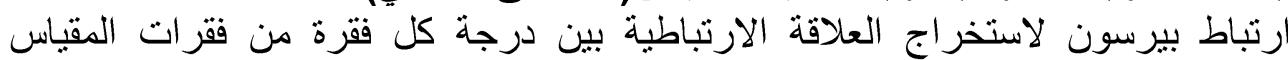

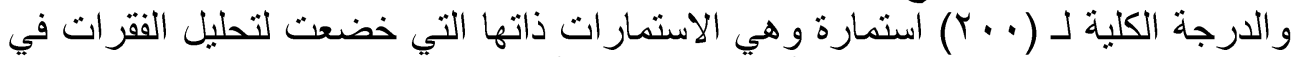

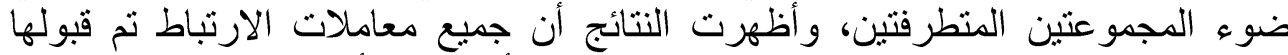

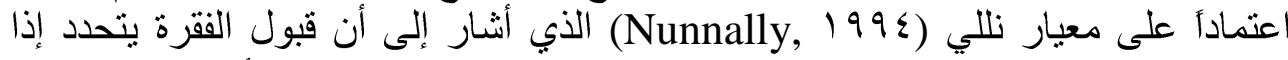

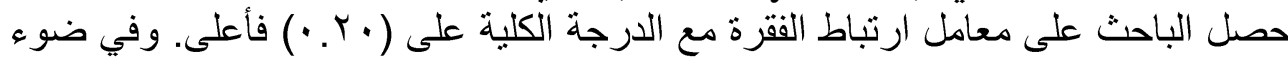

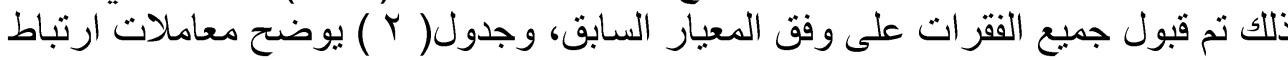

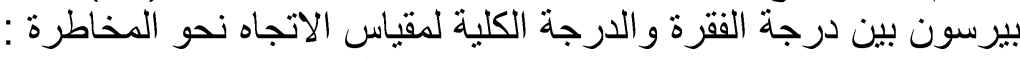

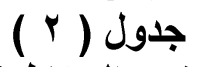

القوة التمبيزية لفقرات مقياس الاتجاه نحو المخاطرة بطريقة المجموعتين المتطرفتين

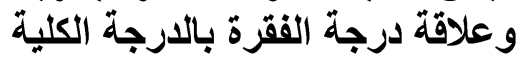

\begin{tabular}{|c|c|c|c|c|c|c|c|}
\hline \multirow[b]{2}{*}{ النتيجة } & \multirow{2}{*}{ معاملة } & \multirow[b]{2}{*}{ القائية } & \multicolumn{2}{|c|}{ المجموعة الدنيا } & \multicolumn{2}{|c|}{ المجموعة العليا } & \multirow[b]{2}{*}{ الفقرة } \\
\hline & & & الانحراف & الحسابي & الالمعياري & الحسابي & \\
\hline دالة & ו ודו & Y.919 & $. \wedge \leqslant .90$ & 5.0110 & $.0 \leqslant \leqslant r r$ & \&.qr०q & 1 \\
\hline دالة &..$\Delta \wedge r$ & $0 . V \cdot \varepsilon$ & $1 . r \wedge 1 \cdot \Lambda$ & $r .9110$ & $. .1 M 4 . \wedge$ & $\leqslant .9110$ & I \\
\hline دالة & $.01 \leqslant$ & $0 . V 7 \varepsilon$ & $1.1700 \leq$ & $\{. .$. & $\cdot .4 \cdot 199$ & $\leq .9 \leq \leqslant \leq$ & $r$ \\
\hline دالة & $\cdot . \leqslant 94$ & 0.191 & $1.4 Y 979$ & $r .9 Y 09$ &. rqY०A & $\varepsilon . q \cdot V \leqslant$ & $\varepsilon$ \\
\hline دالة & $\because .999$ & $\xi . \wedge 9 \wedge$ & $1.5 \% \wedge 1$. & r.AV. \& & $\cdot . \leftrightarrow \Delta \wedge \diamond \wedge$ & $\{. \wedge 019$ & 0 \\
\hline دالة & . & $\leq . r \leq 4$ & $1.7 .9 \mathrm{VY}$ & T. $\leqslant \leqslant \leqslant \leqslant$ & $\cdot \wedge \leqslant .90$ & $\leqslant .0110$ & 4 \\
\hline دالة & $\cdot . \varepsilon \cdot V$ & $7.9 \cdot r$ & $1 . r q \wedge r \wedge$ & 5.1111 & $1 . \leqslant \leq \leqslant Y$ & $r . q \cdot V \leqslant$ & 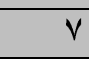 \\
\hline دالة & 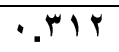 & r.r.r & 1.0119 & $r . \wedge 019$ & . & $\leqslant . \leqslant 110$ & $\Lambda$ \\
\hline دالة & $\because \leqslant .0$ & $0 . V 00$ & $1 . . \leq 79 \leq$ & $\{.1 Y 94$ &. .19 .74 & ะ.97\%. & 9 \\
\hline دالة & $.0 \leq Y$ & $\Lambda .9 \cdot V$ & $1.1 \leqslant 01 \%$ & I.ARrr & 1. MOYVY & $r .9110$ & 1. \\
\hline دالة & $\cdot r V V$ & $0 .+Y \leq$ & $1 . r 19 . r$ & r.V97r & $. .7 \leqslant 941$ & $\varepsilon . V \leqslant \cdot V$ & 11 \\
\hline دالة & $.0 V 7$ & $15 . .11$ & 1. & 1.9110 & $. V \leq 01 Y$ & \&.OrV. & Ir \\
\hline دالة & י.Y4 & $r . \wedge 1$ & $. \wedge Y \leq 17$ & 1.rrrr & $1 . \% \circ 9 \wedge$. & r..... & $1 \%$ \\
\hline دالة & $\cdot . M 1 r$ & $r . V \cdot V$ & $1.101 \wedge Y$ & $\{.4019$ & . YMIYI & $\leq .9 \leq \leqslant \leq$ & $1 \leqslant$ \\
\hline دالة & $.0 \leq 0$ & 14.794 & $1.5 \leq .70$ & r.Y974 &.$J V I q V$ & $\leqslant . \wedge \wedge \wedge q$ & 10 \\
\hline دالة & .091 & $11.74 \leq$ & $1 . r r v \cdot r$ & $1 . \vee \vee \vee \wedge$ & $1 .+1.01$ & $\{. \leqslant Y \circ q$ & 17 \\
\hline دالة &..$\leqslant 1$ & r.797 & $1 . r 0 q r q$ & r.q7r. & $.7 \wedge \leq 01$ & E.VYYY & IV \\
\hline
\end{tabular}




\begin{tabular}{|c|c|c|c|c|c|c|c|}
\hline دالة & $. .54 \leqslant$ & $\varepsilon . \vee \wedge$ & $1 . r \Lambda \cdot r r$ & $\varepsilon .110$ & . MqYI. & $\leq . \wedge 1 \leq \Lambda$ & 11 \\
\hline دالة & $\cdot . E Y r$ & & $1 . r 097 r$ & $\varepsilon .1 Y 94$ &..$\Delta \vee \backslash \wedge \wedge$ & $\varepsilon . \wedge \wedge \wedge q$ & 19 \\
\hline دالة & .00 . & 11.0 .8 & 1.1 .978 & $1 . v \cdot r v$ & 1.11 .01 & $\varepsilon, r \leqslant \cdot V$ & $r$. \\
\hline دالة & $\cdot r \cdot r$ & Y. $\varepsilon q V$ & $1.5 Y 01 \mathrm{~V}$ & $r .7 \wedge \circ r$ & $1 . \Psi \leq \Lambda .7$ & $\varepsilon .1019$ & Y \\
\hline دالة & $. r \leq$. & 0.910 & I.EYYYY & $r .0 V \leq 1$ & $.7 .70 \mathrm{~V}$ & \&.AMrr & rr \\
\hline دالة & $.00 \mathrm{~V}$ & $1 Y .0 \leq 0$ & $1 . \leq r \leq .7$ & $r . \leqslant \wedge 10$ & וYMIYI & $\leq .9 \leq \leq \leq$ & $r r$ \\
\hline دالة & . Mro & $0 . Y \leq Y$ & $1 . r r \leqslant q V$ & 1.7111 & $1.7 \mathrm{Hol}$ & $r . v \leq 1$ & TE \\
\hline دالة & .00 . & $1 Y .19$. & $1 . Y Y \wedge . r$ & $r . r v$. & $. .79 \leq 10$ & $\varepsilon . \leqslant 7 \%$. & ro \\
\hline دالة & $.0 Y \leq$ & $1 . . r \wedge 1$ & $1.1 . V Y \wedge$ & $r .110$ & $1.1 \mathrm{H} 0 \mathrm{~V}$ & $\varepsilon . Y \circ q \mu$ & YY \\
\hline دالة & $. . \leqslant 0 \leqslant$ & $7.1 \% 0$ & 1.1 rras & $r . \wedge I \leq \Lambda$ & . rq & $\varepsilon . \wedge 1 \leq \Lambda$ & rV \\
\hline دالة & $\cdot . \leqslant \wedge 9$ & $7 . \cdots 5$ & $1 . r \leq V q r$ & $r . q \cdot V \varepsilon$ & וYMIYI & $\leq .9 \leq \leq \leq$ & $r \wedge$ \\
\hline
\end{tabular}

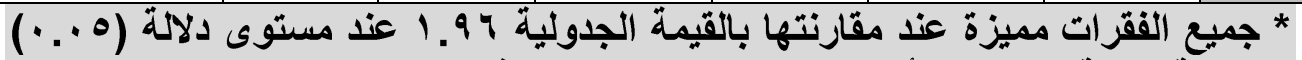

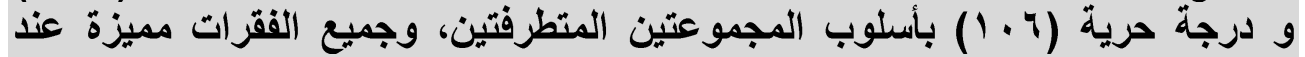

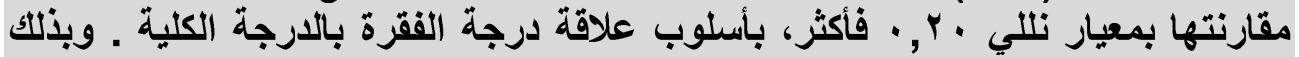

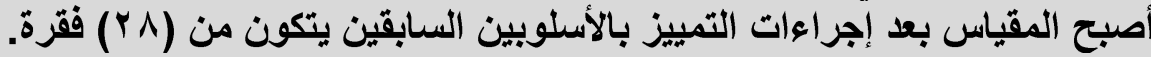

• مؤشرات الصدق : استخرج الباحث الصدق للمقياس الحالي بالاعتماد على المؤشرات الأتية : أنيرات

أ. الصدق الظاهري :تحقق هذا النوع من الصدق عندما عرضت فقرات المقياس الحالي

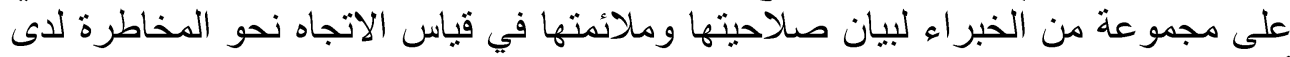
أفر اد عينة البحث.

ب. صدق البناء :تحقق ذلك من خلال استعمال مؤشر علاقة درجة الققرة بالدرجة الكلية

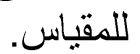

• مؤشرات الثبات :أعتمد الباحث في ايجاد الثبات لمقياس الاتجاه نحو المخاطرة ومجالاته

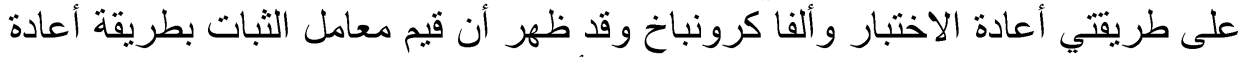

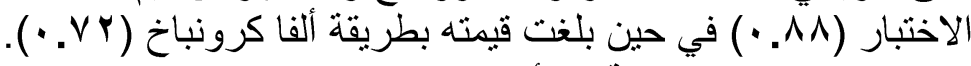

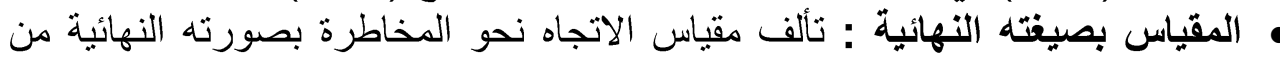
(YV)

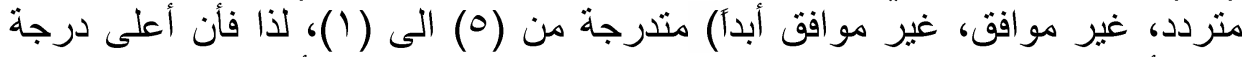

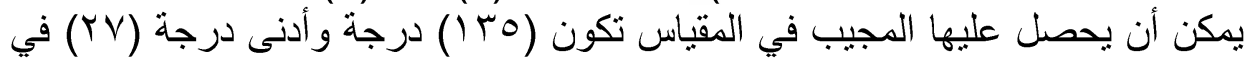

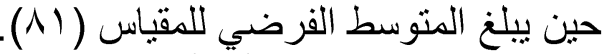

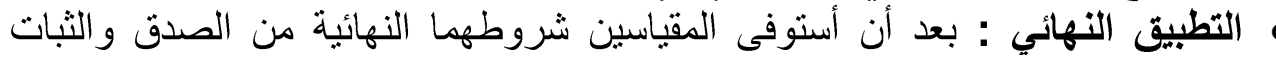

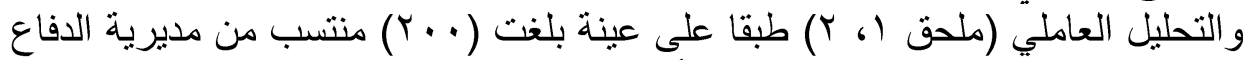

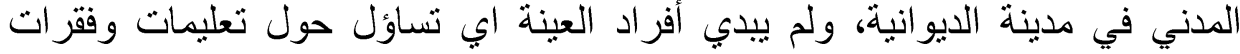

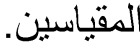
• الوسائل الإحصائية: استععل الباحث في استخراج نتائج البحث الحالي الوسائل الإحصائية الآتية : الإنية ا الاختبار التائي (t-test) لعينتين مستقلتين لحساب القوة التميزية لفقرات المقاييس بطريقة المجمو عتين المتطرفتين. 
Y. معامل ارتباط بيرسون (Person's Correlation Coefficient) لإيجاد معاملات

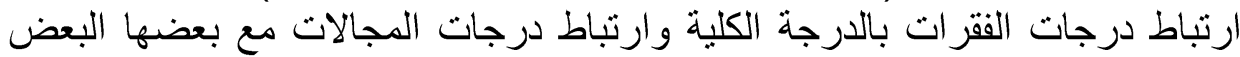
و استخر اج الثبات بطريقة إعادة الاختبار للمقاييس. r. معادلة ألفا كرونباخ (Cronbach-Alpha) لإيجاد الاتساق الداخلي (الثبات بطريقة ألفاكرونباخ). ع. معادلة الخطأ المعياري (Standard Of Error Formula) لاستخر اج الخطأ المعباري لمقاييس البحثث.

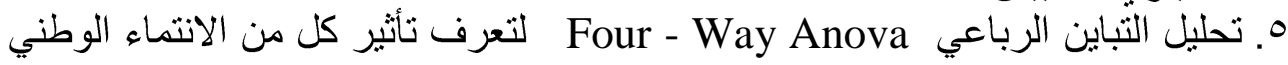

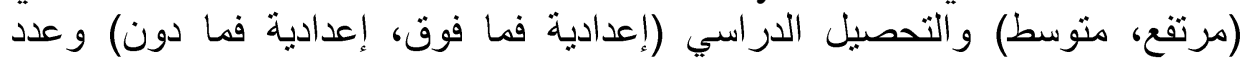

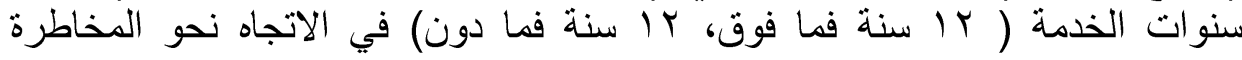
و التفاعل بينهما لكل من متغير ات البحثة البحثة

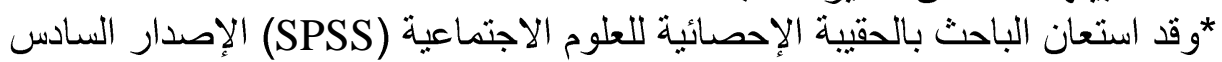

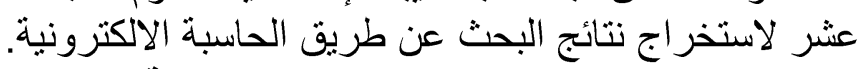

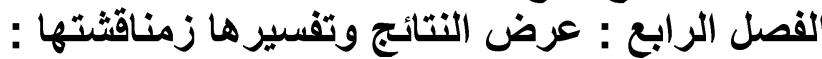

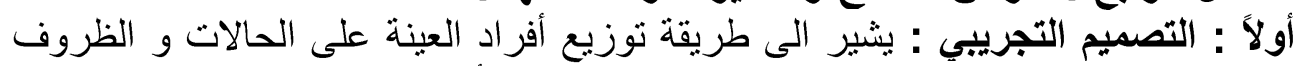

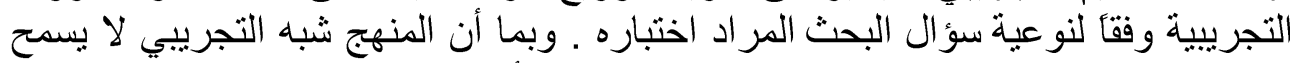

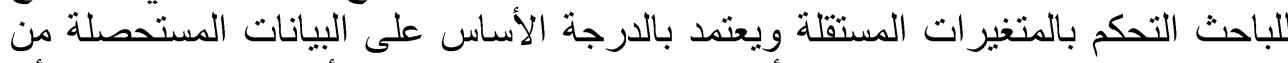

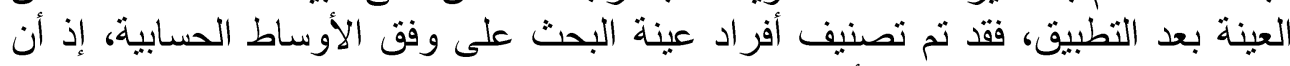

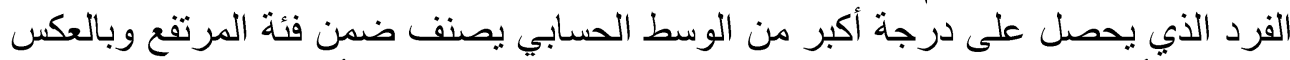

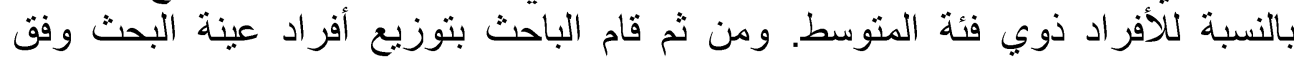

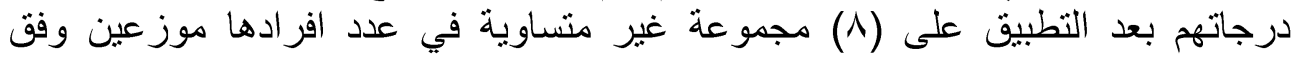

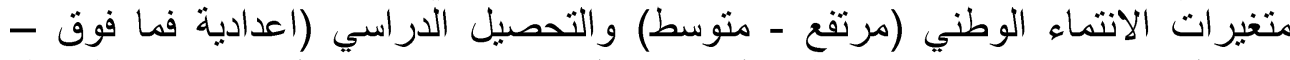

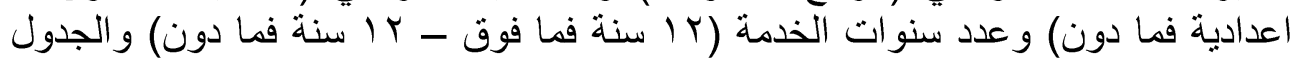

\section{جدول (r)}

\section{يبين التصميم التجريبي على وفثى متفيرات البحث المستقلة}

\begin{tabular}{|c|c|c|c|c|}
\hline \multicolumn{2}{|c|}{ عدد سنوات الخدمة } & \multirow{2}{*}{ التحصيل الدراسي } & & \multirow{6}{*}{ الوطني } \\
\hline rا سنة فما دون & r ا سنة فما فوق & & & \\
\hline ro & $\leq 4$ & اعدادية فما فوق & \multirow{2}{*}{ انتماء مرتفع } & \\
\hline YT & rq & اعدادية فما دون & & \\
\hline 19 & 19 & اعدادية فما فوق & \multirow{2}{*}{ متوسط أتماء } & \\
\hline 10 & $Y \varepsilon$ & اعدادية فما دون & & \\
\hline
\end{tabular}

نحو المخاطرة:

لغرض تعرف نأثير الانتماء الوطني والتحصيل و عدد سنوات الخدمة في الاتجاه

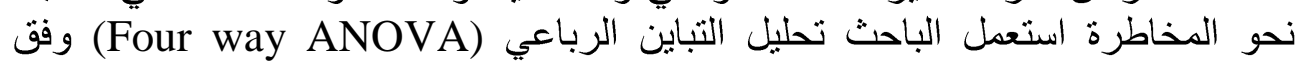

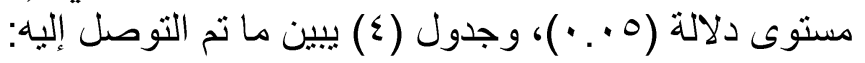




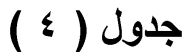

تحليل التباين الرباعي لتعرف تأثير الانتماء الوطني والتحصيل وعدد سنوات الخدمة في

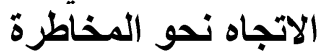

تضح من الجدول (乏) النتائج الآتية :

\begin{tabular}{|c|c|c|c|c|c|c|}
\hline \multirow{2}{*}{ النتيجة } & \multicolumn{2}{|c|}{ الدالة } & \multirow{2}{*}{$\begin{array}{c}\text { المربعات } \\
\text { M-S }\end{array}$} & \multirow{2}{*}{ الحرجية } & \multirow{2}{*}{$\begin{array}{c}\text { مجموع المربعات } \\
\text { S-S }\end{array}$} & \multirow{2}{*}{ مصدر التباين } \\
\hline & الالالة & المحسوبة & & & & \\
\hline دالة &. .0 & $r \leqslant .7 \leqslant r$ & $\leqslant \mid r r . \leqslant \Delta \wedge$ & 1 & $\leqslant I r Y . \leqslant \Delta$ & الانتماء الوطني \\
\hline دالة & $\because \cdot 0$ & 7.009 & $v \wedge \cdot . \Delta r$. & 1 & $v \wedge . . \Delta r$. & التصريل \\
\hline 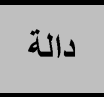 & $\because \cdot 0$ & $\Lambda_{.} \cdot r$. & $90 \leqslant . \leqslant 10$ & 1 & $90 \leq . \leq 10$ & علد سنوات \\
\hline غالة & $\because \cdot 0$ & $.0 r \leq$ & Tr.ras & 1 & Tr.ras & * الخدمة * التحصيل \\
\hline - & - & & $\cdots r$ & $1 \wedge \varepsilon$ & KT.10.MYT & الخطأ \\
\hline- & - & & $r \ldots$ & & $r \leq r v \leqslant q r . .$. & المجموع \\
\hline- & - & & 199 & & $r \leq \leqslant . r . r \Delta 0$ & مجموع الارتباط \\
\hline
\end{tabular}

إ. تأثير الانتماء الوطني (مرتفع - متوسط) في الاتجاه نحو المخاطرة :

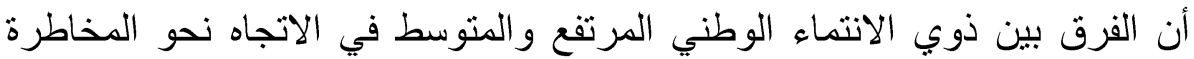

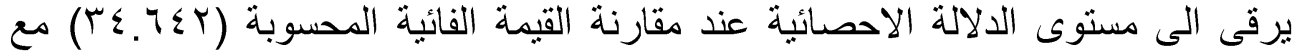

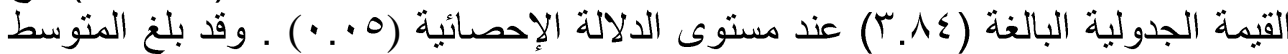

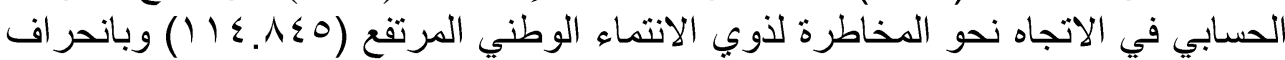

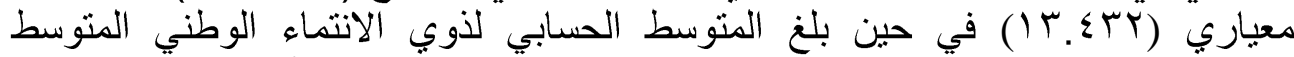

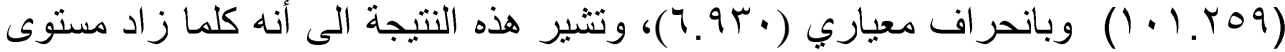

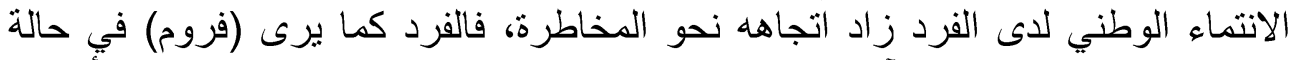

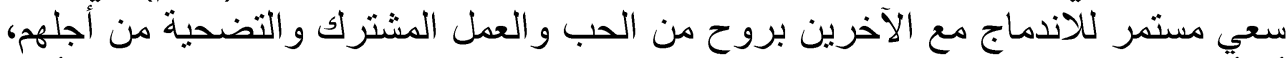

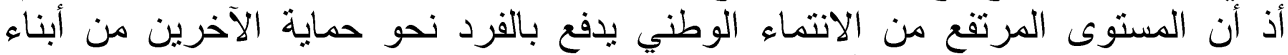

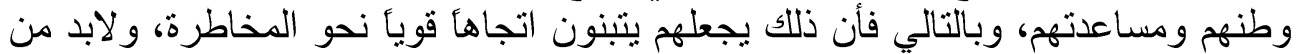

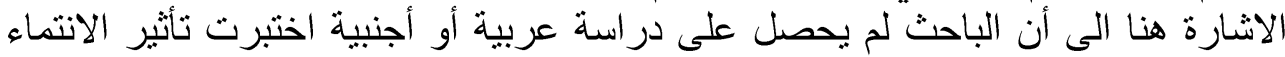

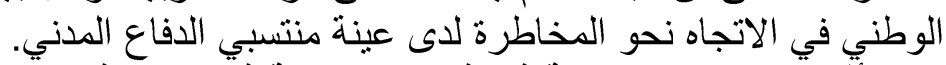

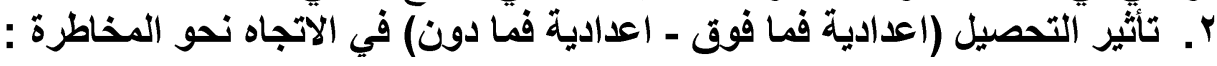

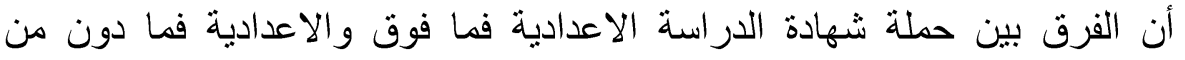

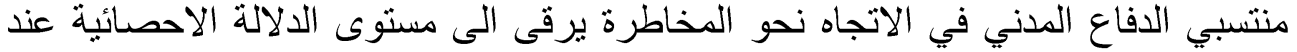

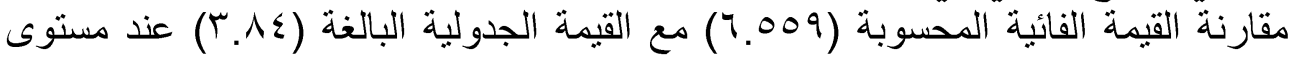

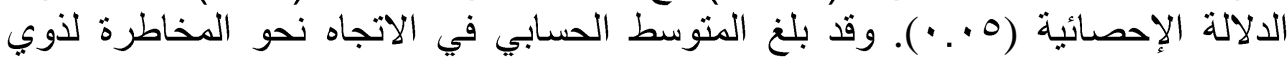

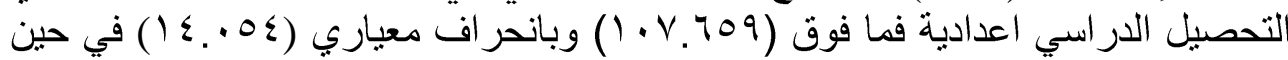




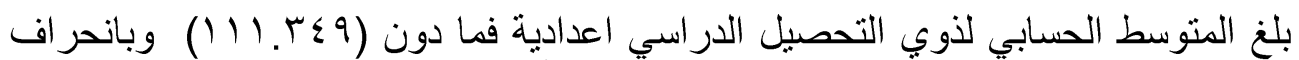

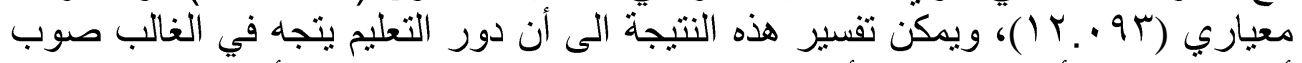

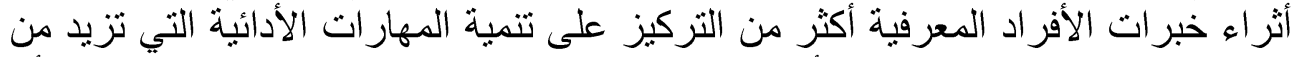

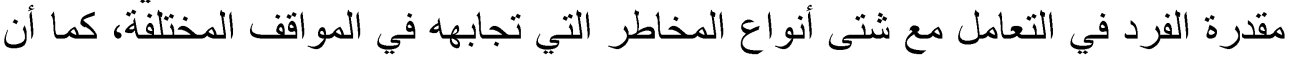

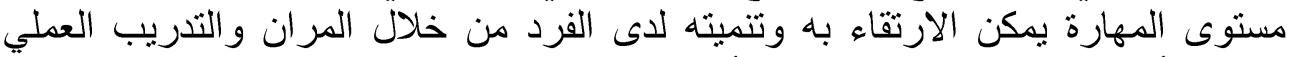

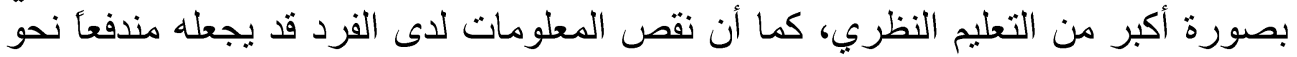

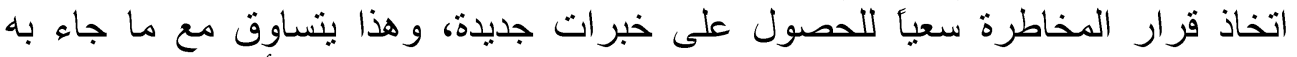

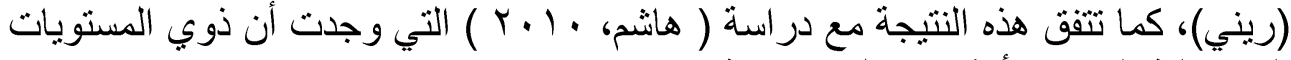

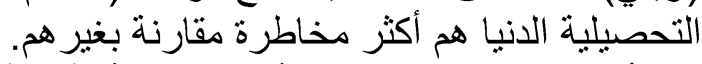

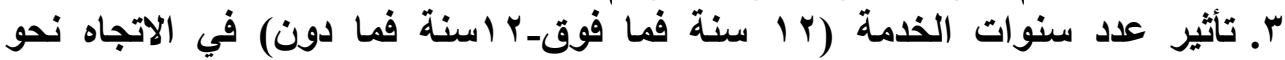

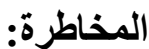

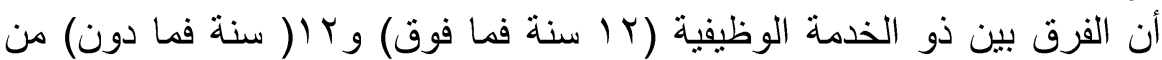

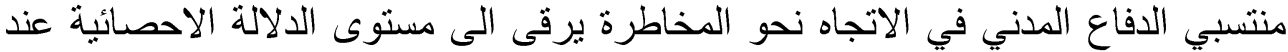

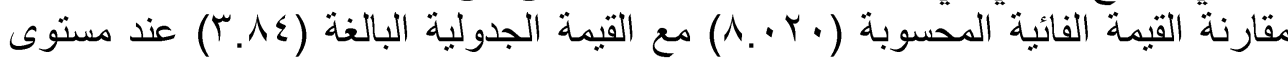

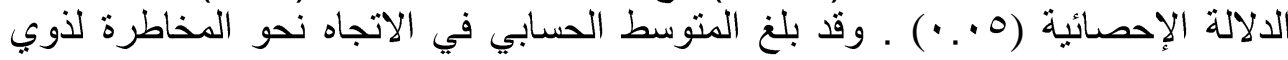

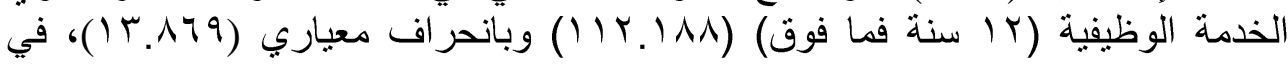

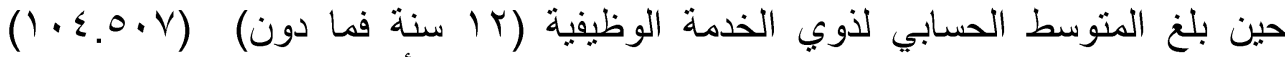

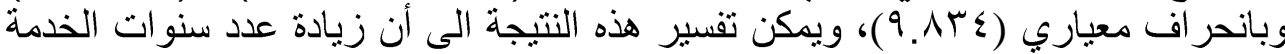

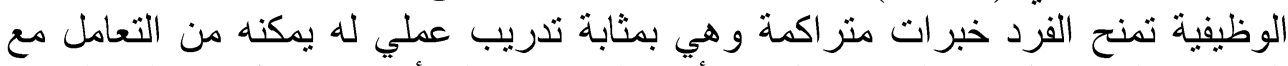

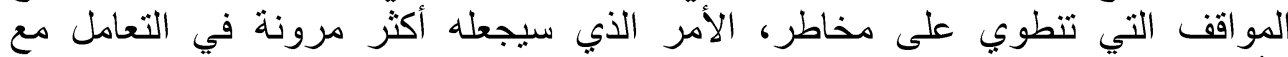

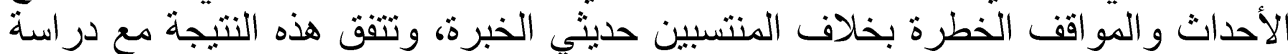

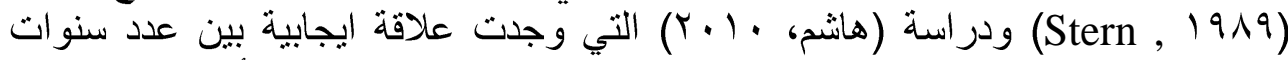

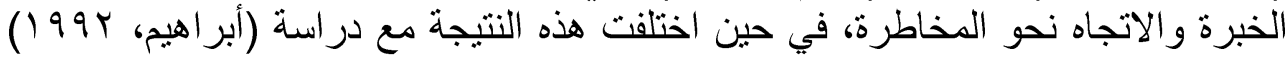

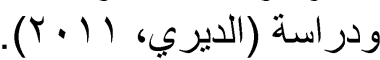

ع. تأثير تفاعل الانتماء الوطني والتحصيل الاراسي والخدمة الوظيفية في الاتجاه نحو المخاطرة : المأيز

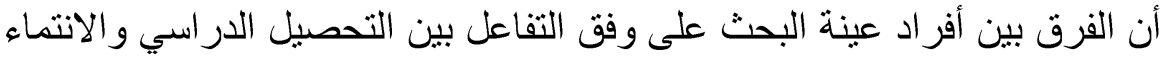

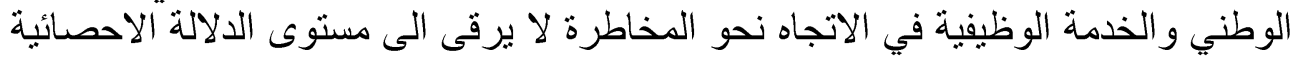

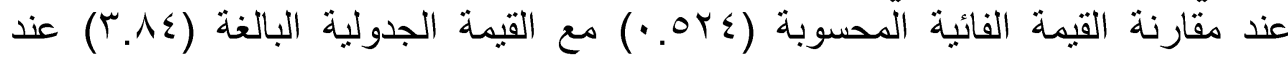

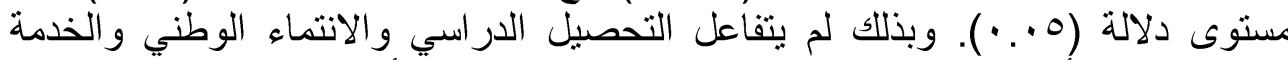

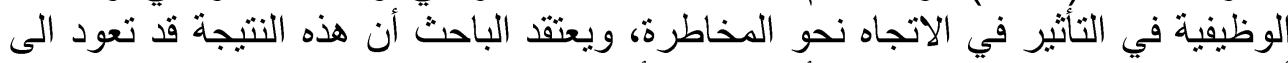

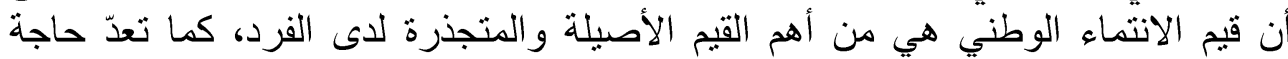

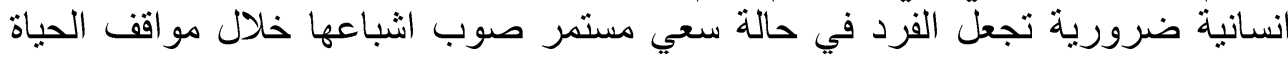

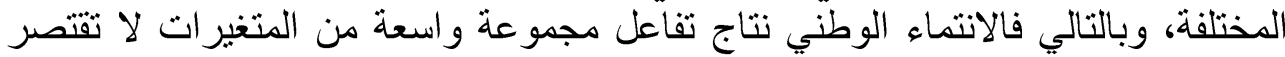

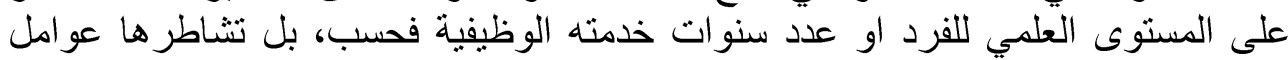

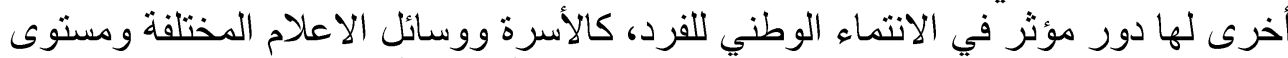

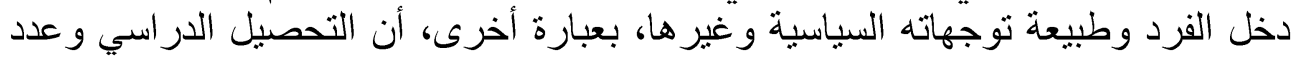

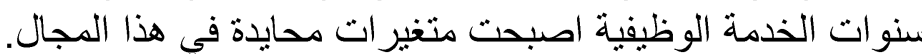

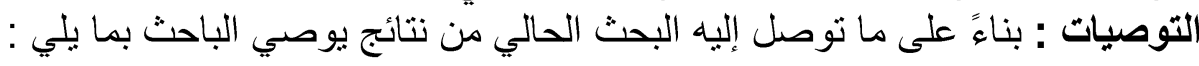


ا ـ إثراء المناهج الدراسية بالمفاهيم والقيم الوطنية الرصينة، التي تعزز من قيم الانتماء

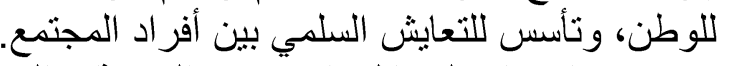

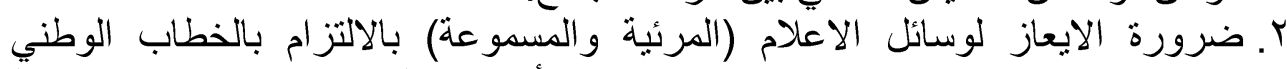

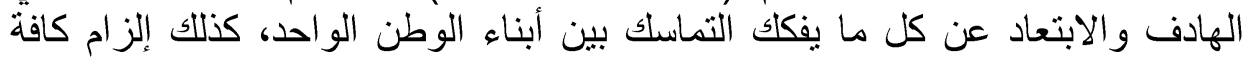

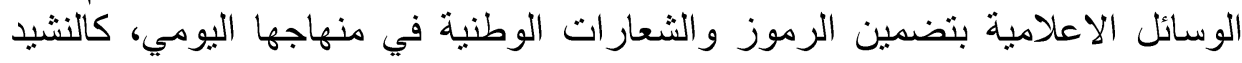

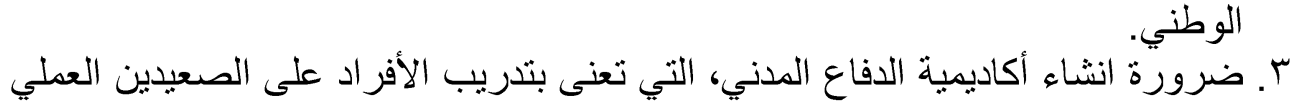

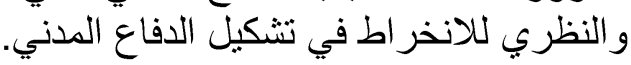

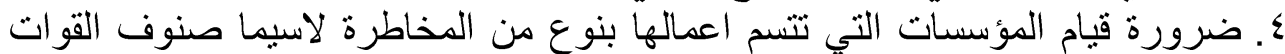

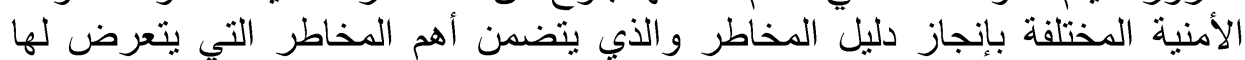

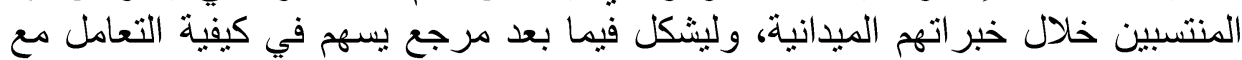

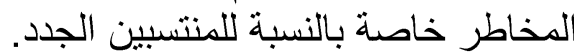
المقترحات : يقترح الباحث إجر اء الدراسين السات الآتية والتي أستقر أها خلال انجاز البحث لما

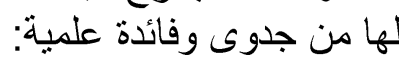
ا ـ دراسة مماثلة للار اسة الحالية على على عينات ذات نماس مباشر مع الخطر كالجيش و الشرطة بمختلف صنوفة دهم. r. دراسة تأثير متغير ات أخرى في الاتجاه نحو المخاطرة لم يتناولها البحث الحالي كمستوى الدخل و الرتبة و الجنس والترى الصنف.

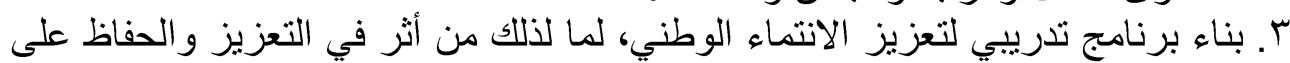

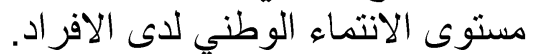




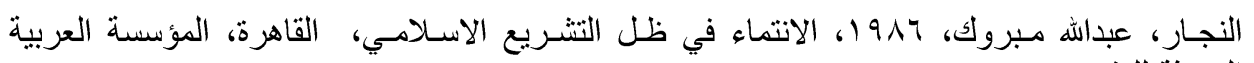

- Adams, g.s, 197£, Measurement and evaluation Education Psychology and Guidance, Hol, New York.

- Anstasi, A, $19 \vee 7$, Psychological Testing, $\varepsilon^{\text {th }}$. ed, New York, Macmillan Publishing, INC.

- Eble, R, $19 \mathrm{Vr}$, Essentials of Educational Measurement, New Jersey.

- Ghiselli, E \& et.al, 19^1, Measurement theory for the behavioral sciences, san francies \& company.

- Hendricky, X, L, 1991, Perceived control nature of risk information and Risk - Taking, New York.

- Hopkins, J \& Comsis, C, 1990, Understanding Youthful Risk Taking and Driving, Interim Report, Vol.r ${ }^{r}$, No. ${ }^{q}$, Baltimore, Maryland.

- Irwin, C. E. 199 Bell (Eds.), Adolescent risk taking, pp. $\vee_{-} \uparrow \wedge$, Newbury Park, CA: Sage Publications.

- Kasperson, Jeanne, X \& Kasperson, Roger E, Y. . o, Social features of risk, Volume 1: Public and communication related to risks and social amplification of risks. Earthscan, Virginia.

- Kogan , N \& Wallach, M, 197V, Risk - taking as function of the Situation, the Person and the group, new York.

- Mary, Bell , Y.l乏, Risk Orientation and Risk-Taking Behavior: The Impact of Race/Ethnicity and Gender on Mental Health and Substance Use among Young Adults, Nashville, Tennessee.

- Nunnally, J . G, $19 \vee \wedge$, Psychometric theory, $r^{\text {nd }}$, Edition, New York, McGraw - Hill.

- Renney, T. $199 \varepsilon$, Models of driving behavior: A review of their evolution. Accident Analysis and Prevention, Vol. ${ }^{\top}$, No. 7, pp: VTr-VO.

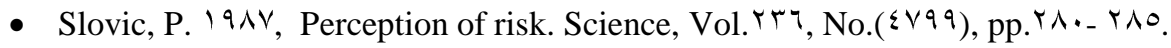




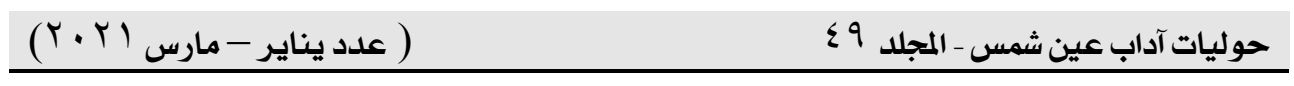

الملاحق

ملحق رقم ( 1 ) مقياس الانتماء الوطني

\begin{tabular}{|c|c|c|c|c|c|c|}
\hline تنطيقي & تلّيّ نادراً & تنطبيّ & علىيّ غالبًاً & تنطبيّ & 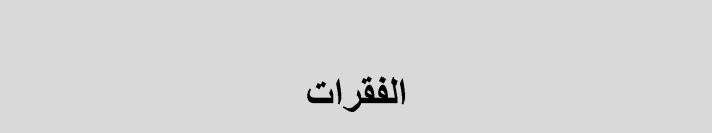 & $ت$ \\
\hline & & & & & أملاي ان ارى بلاي يحيى بأمان. & 1 \\
\hline & & & & & اضحي من اجل صون حياة مواطني بلدي. & $r$ \\
\hline & & & & & اثمن تضحيات الثهداء بأرواحهم من اجل الوطن. & $r$ \\
\hline & & & & & استوحش العيش خارج الوطن. & $\varepsilon$ \\
\hline & & & & & انتقد الاشخاص الذين هاجروا عن بلادهم. & 0 \\
\hline & & & & & والثاركب مع ابناء وطني في الأهداف والحقوق & 9 \\
\hline & & & & & اشارك في حملات العمل التطوعي. & $\mathrm{V}$ \\
\hline & & & & & يصعب علَّيّ الانسجام مع قيم وتقاليّا مجتمعي. & $\Lambda$ \\
\hline & & & & & لم احصل من بلدي على ما استحقه. & 9 \\
\hline & & & & & افتخر بحضارة بلدي وتأريخه. & 1. \\
\hline & & & & & الآخرين. وفق معتقاتي دون مراعاة معتقات & 11 \\
\hline & & & & & اشعر بالاغتراب حتى حينما اكون بين الناس. & Ir \\
\hline & & & & & افضل الصداقات التي كونتها هي من مواطني بلدي. & ir \\
\hline & & & & & انزعج حينما اسمع ما يسيء لوطني. & $1 \varepsilon$ \\
\hline & & & & & اضحي بكل ما أملتك من أجل وطني. & 10 \\
\hline & & & & & والفعاليّي مشاركة بتص تمض الوحدة الموطنية. في التظاهرات & 17 \\
\hline & & & & & اعمل على تشجيع الصناعية الوطنية. & IV \\
\hline & & & & & لا اميل الى التفكير في حل مشكلات وطني. & 11 \\
\hline & & & & & والتعصب. كل من حولي على الوحدة ونبذ التفرقة & 19 \\
\hline & & & & & المحافظة على ممتلكات الدولة واجب وطني. & $r \cdot$ \\
\hline & & & & & تحركات مشبوهة الملاغ الجهات المن الوطتصة حينما ارى اي & YI \\
\hline & & & & & للنشير الوطني. عندما اشاهد علم بلاي او استمع & Yr \\
\hline & & & & & وطمياة في وطني غير مجدية ولا تحقق احلامي & $r r$ \\
\hline & & & & & اتفاني في التضحية لصون مقدسات بلدي. & $r \varepsilon$ \\
\hline & & & & & حمايةة الوطن تقع على عاتق رجال الامن فقط. & ro \\
\hline & & & & & عملي، لان ذنتك سيحسب حيال بذل المزئ من الجهود في & $r q$ \\
\hline & & & & & من وارض المشاركة في حملات في المال العمل التطوعي، لأنها & $r V$ \\
\hline
\end{tabular}


ملحق رقم ( Y ) مقياس الاتجاه نحو المخاطرة

\begin{tabular}{|c|c|c|c|c|c|c|}
\hline غير موافق & موافير & متردد & موافق & موافق & 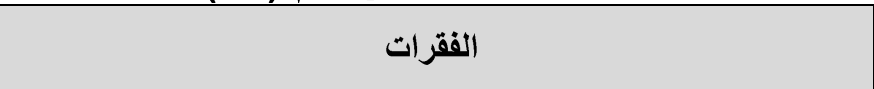 & $ت$ \\
\hline & & & & & أثشعر بالارتياح عندما أنقذ حياة المواطنين من الخطر. & 1 \\
\hline & & & & & أحب أن أكون في مقدمة زملائي لإنقاذ حياة الناس. & r \\
\hline & & & & & لثقي بنفسي تزداد وقت الخطر. & $r$ \\
\hline & & & & & لا أخشى عواقب الأمور، عندما يتعلق الامر بإنقاذ ارواح المواطنين. & $\varepsilon$ \\
\hline & & & & & اذركز عصل تفجير ارهابي وكنت في اجازة، أسارع الى الإلتحاق الى & - \\
\hline & & & & & أميل الى العقل في المناطق الساخنة أكثر من المناطق الآمنة. & 9 \\
\hline & & & & & ينتابني الخوف من الموت أَثناء أدائي أحد واجباتي. & $\mathrm{V}$ \\
\hline & & & & & يزداد حماسي عندما يتم اختياري لأحدَ الواجبات الَّطرة. & $\Lambda$ \\
\hline & & & & & تزداد عزيمتي أكثر عند روئة المصابين لمساعدتهم. & 9 \\
\hline & & & & & اشعر بزيادة ضربات القلب عند التوجه الى الواجب. & 1. \\
\hline & & & & & عند ادائي للواجب ينحصر تفكيري فيه فقط. & 11 \\
\hline & & & & & أثنعر بضيق التنفس عند تكليفي بواجب خطر. & IT \\
\hline & & & & & أفضل العمل الجماعي أكثر من العمل بمفردي أثثاء أدائي واجبي. & Ir \\
\hline & & & & & أواظب على قراءة بعض الآيات القر آنية والأدعية اثناء الّواجب. & $1 \leq$ \\
\hline & & & & & أتذمر من تكليفي بالواجب. & 10 \\
\hline & & & & & أحب الأعمال والههن الإدارية أكثر من عملي. & 17 \\
\hline & & & & & أؤمن بأن المواجهة هي افضل خيار للتظلب على الصعوبات في عملي. & IV \\
\hline & & & & & اسيطر على مشاعزي اثثاء اداء الواجب، لأركز فيه أكثر. & $1 \wedge$ \\
\hline & & & & & الواجب بإتقاذ حياة المواطنين أكثر من اهتمامي بالوقت الذي يستغرقه & 19 \\
\hline & & & & & افكر بما سيلحقتي من ضرر اثثاء إنقاذ المصابين. & $r \cdot$ \\
\hline & & & & & عملي ينسجم مع آفكاري ومحتقداتي. & YT \\
\hline & & & & & تنتابني الرغبة بترك عملي. & YY \\
\hline & & & & & والقوم باداء و واجبي دون ارتداء واقي الصدمات وخوذة الرأس & YT \\
\hline & & & & & اشعر بالخوف اذا كان واجبي في الاماكن المرتفعة. & $r \leq$ \\
\hline & & & & & اخثى انهيار المبنى اثثاء اطَفاء الحرائق او انقاذ الناس. & ro \\
\hline & & & & & مشاركتي في الدورات التّريبية طورت مهارتي ومستوى إدائي. & rt \\
\hline & & & & & التفيذا باله. & TV \\
\hline
\end{tabular}

